\title{
Enhancing the Magnetization, Dielectric Loss and Photocatalytic Activity of Co-cu Ferrite Nanoparticles Via the Substitution of Rare Earth Ions
}

\section{M.A.Abdo ( $\nabla$ mhmd_ahmd20@yahoo.com )}

Zagazig University Faculty of Science https://orcid.org/0000-0001-5883-0259

\section{S.F. Mansour}

Zagazig University Faculty of Science

\section{Faten Al-Hazmi}

King Abdulaziz University

\section{M.S. AlHammad}

King Abdulaziz University

\section{M.S. Sadeq}

Sinai University

\section{Research Article}

Keywords: CCL, RhB, nanocrystals synthesized, STEM-EDX, anisotropy

Posted Date: August 5th, 2021

DOI: https://doi.org/10.21203/rs.3.rs-770192/v1

License: (c) (i) This work is licensed under a Creative Commons Attribution 4.0 International License. Read Full License 


\section{Abstract}

This study reports the impact of lanthanum substituted Co-Cu ferrite nanoparticles on the RhB dye disposal. Moreover, a complete investigation for the structural, magnetic and optical properties for $\mathrm{Co}_{0.5} \mathrm{Cu}_{0.5} \mathrm{La}_{\mathrm{x}} \mathrm{Fe}_{2-\mathrm{x}} \mathrm{O}_{4}(\mathrm{CCL})$ nanoferrites was executed. These nanocrystals synthesized via a combustion approach with a peculiar lattice parameter behavior; which discussed through three hypotheses. STEMEDX micrographs of some selective samples confirm the nanocrystalline nature with presence of all constituents' chemical elements CCL nanoferrites. The saturation magnetization of CCL nanoferrites was tuned with $\mathrm{La}^{3+}$ ions substitution. Contrary to the expected results, anisotropy constant introduced a decrement behavior with $\mathrm{La} / \mathrm{Fe}$ substitution process. The microwave frequency $\left(\omega_{M}\right)$ values for all $\mathrm{CCL}$ nanoparticles are in the range $11.87 \mathrm{GHz}-9.46 \mathrm{GHz}$. The band gap has a peculiar behavior; a red shift and followed by a blue one. Through photodegradation testing, we explicate the RhB degradation mechanisms over our CCL nanoferrites. The nanoferrite $\mathrm{Co}_{0.5} \mathrm{Cu}_{0.5} \mathrm{La}_{0.15} \mathrm{Fe}_{1.85} \mathrm{O}_{4}$ has a moderate saturation magnetization, highest coercivity, and lowest loss which is a suitable candidate for data recording applications, furthermore can be utilized as a photocatalyst for RhB effluents removal with degradation efficiency $94.50 \%$ at 180 min solar radiation.

\section{Introduction}

In day-to-day life environmental pollution from organic dyes became an intractable problem. Particularly, rhodamine $\mathrm{B}(\mathrm{RhB})$ organic dye can be vastly utilized in diverse purposes. Physically, RhB is bright-red in color with molecular formula $\mathrm{C}_{28} \mathrm{H}_{31} \mathrm{ClN}_{2} \mathrm{O}_{3}$, molecular weight $479 \mathrm{~g} / \mathrm{mol}$ and water solubility $(8-15 \mathrm{~g} / \mathrm{L}$ at $20^{\circ} \mathrm{C}$ ). In fact, RhB can cause reliable environmental problems, besides its capability to make skin or eyes irritation [1]. All these factors motivate us to generate effectual and cost-effective removal technique to overcome this environmental threat. Photocatalytic degradation of dyes using spinel ferrite nanoparticles is a salutary and environmentally friendly approach for dyes removal [2]. Recently, researches focus in the field of utilizing spinel ferrites as catalysis due to its moderately narrower band gap ( $2.0 \mathrm{eV}$ ), where can absorb both Vis. and UV radiations [3]. Moreover, the magnetic nature of spinel ferrites empowering its easy separation and retrieval of the ferrite powder again [4]. Kefeni et al., [5] declared that cobalt and copper ferrites $\left(\mathrm{CoFe}_{2} \mathrm{O}_{4} \& \mathrm{CuFe}_{2} \mathrm{O}_{4}\right)$ besides their corresponding composites introduce higher photocatalytic performances. Consequently, we got excited to exploit a new nanoferrite containing both cobalt and copper cations $\left(\mathrm{Co}_{0.5} \mathrm{Cu}_{0.5} \mathrm{Fe}_{2} \mathrm{O}_{4}\right)$ which doping with a rare earth element to augment their overall photocatalytic performance. Rather than their catalytic performances, $\mathrm{Co}_{0.5} \mathrm{Cu}_{0.5} \mathrm{Fe}_{2} \mathrm{O}_{4}$, also, acquire amazing properties among the reminder ferrite types [6]. Indeed, $\mathrm{CoFe}_{2} \mathrm{O}_{4}$ is a promising material for diverse implementations based on its highest magneto-crystalline anisotropy $\left(\sim 3 \times 10^{5} \mathrm{~J}^{-\mathrm{m}^{-3}}\right)$ [7]. This property make $\mathrm{CoFe}_{2} \mathrm{O}_{4}$ has a feature suitable for storage devices applications. Basically, the crucial necessity for these magnetic materials utilizing in storage data that it should been have moderate saturation magnetization and high coercivity $\left(\mathrm{H}_{\mathrm{C}}\right)$, which are satisfied in $\mathrm{CoFe}_{2} \mathrm{O}_{4}$ nanoparticles [8]. Additionally, $\mathrm{CuFe}_{2} \mathrm{O}_{4}$ nanoparticles with the Jahn-Teller ion $\left(\mathrm{Cu}^{2+}\right)$ have ubiquitous 
applications; based on their magneto-strictive property for the ferrite material [9]. Hence, in this investigation, by choosing $\mathrm{Co}_{0.5} \mathrm{Cu}_{0.5} \mathrm{Fe}_{2} \mathrm{O}_{4}$ nanoferrite to be the pristine sample we can obtain the two features producing high $\mathrm{H}_{\mathrm{C}}$; higher magneto-crystalline anisotropy (by $\mathrm{CoFe}_{2} \mathrm{O}_{4}$ ) besides higher magnetostrictive property (by $\mathrm{CuFe}_{2} \mathrm{O}_{4}$ ). Generally, Rare earth elements have auspicious effect on enhancement diverse nanoferrite systems [10-12]. Our research group, in the previous publication, declared that the substitution of lanthanum (La), as a rare earth element, into Zn-Mg ferrite system enhanced its physical properties besides improving its degradation efficiency [13]. So, we are enthused to use La ion to enhance the features of another nanoferrites system as $\mathrm{Co}_{0.5} \mathrm{Cu}_{0.5} \mathrm{La}_{\mathrm{x}} \mathrm{Fe}_{2-\mathrm{x}} \mathrm{O}_{4}$. Thus, by adding $\mathrm{La}^{3+}$ ions, it is expected to obtain the following results; (1) moderate value of magnetization, where $\mathrm{La}^{3+}$ ions have lower magnetic moment than $\mathrm{Fe}^{3+}$ ions; (2) high value of coercivity, where $\mathrm{La}^{3+}$ ions will generate spin-orbit coupling between $4 \mathrm{f}$ and $3 \mathrm{~d}$ levels; (3) diminishing the energy gap, by energy levels creation by lanthanum electrons inside band gap, and interns enhance the photocatalytic property. In view of hopeful properties of spinel ferrite nanoparticles, current research investigates structural, magnetoelectric, optical features besides photocatalytic activity of $\mathrm{Co}_{0.5} \mathrm{Cu}_{0.5} \mathrm{La}_{x} \mathrm{Fe}_{2-\mathrm{x}} \mathrm{O}_{4}$ nanoparticles; which is not investigated until now.

\section{Materials And Methods}

Pure and $\mathrm{La}^{3+}$ subrogated $\mathrm{Co}_{0.5} \mathrm{Cu}_{0.5} \mathrm{Fe}_{2} \mathrm{O}_{4}$ nanoferrites were prepared through citrate combustion technique. In this approach metals nitrate; cobalt, copper, iron, lanthanum, with definite amounts, in addition to citric acid and ammonia solution were used. The combustion process of $\mathrm{Co}_{0.5} \mathrm{Cu}_{0.5} \mathrm{La}_{\mathrm{x}} \mathrm{Fe}_{2-\mathrm{x}} \mathrm{O}_{4}(\mathrm{CCL}) ;(0 \leq \mathrm{x} \leq 0.15$; step 0.03$)$ ferrite nanoparticles are reported minutely in an earlier publication [14]. The yield CCL nanoferrites were investigated by XRD, FTIR, STEM-EDX besides its sundry features; dielectric, magnetic, optical and photocatalytic activity using the identical instruments in previous works $[13,15]$.

\section{Results And Discussion}

\subsection{Structural and morphologic investigations 3.1.1. XRD analysis}

Figure 1 manifests the XRD diffractograms of $\mathrm{Co}_{0.5} \mathrm{Cu}_{0.5} \mathrm{La}_{x} \mathrm{Fe}_{2-\mathrm{x}} \mathrm{O}_{4}(\mathrm{CCL}) ;(0 \leq \mathrm{x} \leq 0.15)$ ferrite nanoparticles. The chart of pristine $\mathrm{Co}_{0.5} \mathrm{Cu}_{0.5} \mathrm{Fe}_{2} \mathrm{O}_{4}$ nanoferrite sample $(\mathrm{x}=0.0)$ gives peaks at diffraction angles $2 \theta=18.3,30.26,35.65,37.20,43.30,53.60,57.20,62.80$ and 74.24 that indexed to Miller notations as; $111,220,311,222,400,422,511,440$ and 533 in that order. Actually, these diffraction peaks are totally indexed to the FCC spinel lattice conforming to JCPDS cards (00-001-1121 and 01-0770010). Also, the XRD of the reminder $\mathrm{Co}_{0.5} \mathrm{Cu}_{0.5} \mathrm{La}_{\mathrm{x}} \mathrm{Fe}_{2-\mathrm{x}} \mathrm{O}_{4}$ ferrite nanoparticles have diffraction peaks congruous to those observed in the pristine sample with slightly shift for diffraction angles; which 
confirm the spinel structure for all CCL nanoferrites. The substitution of $\mathrm{La}^{3+}$ not produces any impurities, or foreign phase; confirming the wholly dissolution of $\mathrm{La}^{3+}$ ions in CCL spinel lattice. Furthermore, the peaks are sharp and spread over the XRD patterns; affirming the nanocrystalline nature for all the investigated CCL nanoferrites.

The lattice parameter $\left(\mathrm{a}_{\text {exp }}\right)$ for all $\mathrm{Co}_{0.5} \mathrm{Cu}_{0.5} \mathrm{La}_{\mathrm{x}} \mathrm{Fe}_{2-\mathrm{x}} \mathrm{O}_{4}$ nanoparticles is calculated using the related Eq. in [16]. Although the substitution process is a larger ion, $\mathrm{La}^{3+}(1.032 \AA)$, instead of a smaller one, $\mathrm{Fe}^{3+}$ $(0.645 \AA)$ [17], the lattice parameter did not introduce an increment behavior. It has a peculiar trend; decrement from $(8.375 \AA$ at $x=0.0)-(8.327 \AA$ at $x=0.12)$ and augment for the nanoferrite with $x=0.15$ to $8.375 \AA$, see Fig. 2 . Three hypotheses are further suggested to interpret this enigma; two for the decrement behavior and one for the increment situation. Firstly, microstrains are the reason for the $a_{\text {exp }}$ decrement behavior, where make a compensation role against the large predictable crystal expansion. In fact, $\mathrm{La}^{3+}$ ions (with its large radius) tend to enlarge the $a_{\exp }$ values, then as a reparations for this alteration in spinel lattice, strain attempts to reduce it $[18,19]$. Mariosi et al. [20], reported alike behavior for decreasing lattice parameter of $\mathrm{CoLa}_{\mathrm{x}} \mathrm{Fe}_{2-\mathrm{x}} \mathrm{O}_{4}$ ferrite nanoparticles and explicated its behavior using the same reason. Secondly, bond dissociation energy $(\mathrm{BDE})$ is another factor for interpreting this decrement behavior. In fact, BDE of $(\mathrm{La}-0)$ is $(619 \mathrm{~kJ} / \mathrm{mol})$ which be larger than that of $(\mathrm{Fe}-0)(409 \mathrm{~kJ} / \mathrm{mol})$ [21]. Consequently, the La-O bond is shortened and sturdy; therefore, CCL lattice volume and consequently its parameter are decreased. As for the third hypothesis, it will be for the nanoferrite with $x=0.15$; where its $a_{\exp }$ increment behavior can be interpreted in view of cations redistribution between tetrahedral $(A)$ and octahedral (B) positions in CCL ferrite lattice. Actually, the ionic radii at A-sites are $r_{A}\left(C^{2+} 0.58=(\AA\right.$, $r_{A}\left(C^{2+} 0.57=\left(\AA, r_{A}\left(F^{3+} 0.49=\left(\AA\right.\right.\right.\right.$, and at B-sites are $r_{B}\left(C^{2+} 0.745=\left(\AA, r_{B}\left(C^{2+} 0.73=\left(\AA, r_{B}\left(F^{3+} 0.645=(\right.\right.\right.\right.\right.$ $\AA, r_{B}\left(L^{3+} 1.032=\left(\AA\right.\right.$ [17]. Then, the larger La cations will situate in B-site at expense of $\mathrm{Fe}^{3+}$ ones, which forced some $\mathrm{Fe}^{3+}$ cations to emigrate from $\mathrm{B}$ - to $\mathrm{A}$-sites and consequently some $\mathrm{Co}^{2+}$ and $\mathrm{Cu}^{2+}$, with their larger radii in $B$ sites rather than in A-sites, will transfer from $A$ - to B-sites; producing $a_{\text {exp }}$ increment behavior for the nanoferrite with $(x=0.15)$. Ounacer et al. [22], declared a similar attitude and expound its result with the same reasoning.

Although, crystallite size can be determined by diverse methods; Rietvled, Williamson-Hall (W-H) or Scherrer's formula, W-H method is the most convenient one, because the strain components are involved. Consequently, the crystallite size $\left(D_{W-H}\right)$ besides lattice strain $\left(\varepsilon_{\mathrm{s}}\right)$ of CCL ferrite nanoparticles is determined using Williamson-Hall method. Figure 3(a-f) shows the W-H graphs for all CCL nanoferrites, concerning the obtained diffraction peaks, with their better linear fitting; for determining crystallite size from intercept and lattice strain from the slope. Then crystallite size of CCL nanoferrites introduces distinctive trend; increment from $20.94 \mathrm{~nm}$ (at $\mathrm{x}=0.0$ ) to $33.01 \mathrm{~nm}$ (at $\mathrm{x}=0.09$ ) and then decrease step forward for $x=0.12$ and 0.15 to $30.27 \mathrm{~nm}$ and $28.41 \mathrm{~nm}$, respectively; see Fig. 2 . This means that for small $\mathrm{La}^{3+}$ content, up to the nanoferrite with $\mathrm{x}=0.09$, the rates of nucleation and growth steps increase producing large size for crystallites [23]. Therefore, the high concentrations of $\mathrm{La}^{3+}$ ions $(x=0.12$ and Loading [MathJax]/jax/output/CommonHTML/jax.js prain boundaries pinning, and interns shackle grain growth; 
resulting decreasing crystallite size trend for these two nanoferrite samples. On the other hand, lattice strains of CCL nanoferrites have positive values, see Fig. 2; demonstrating that all CCL nanoferrites possessing tensile strain with increasing values up to $\mathrm{x}=0.09$ and then decrease for further $\mathrm{La}^{3+}$ substitution. This increment behavior of lattice strain confirms the first hypothesis for lattice parameter decrement; as discussed above.

\subsubsection{Morphological characterization}

The STEM-EDX of some selective samples, $\mathrm{Co}_{0.5} \mathrm{Cu}_{0.5} \mathrm{Fe}_{2} \mathrm{O}_{4}, \mathrm{Co}_{0.5} \mathrm{Cu}_{0.5} \mathrm{La}_{0.09} \mathrm{Fe}_{1.91} \mathrm{O}_{4}$ and $\mathrm{Co}_{0.5} \mathrm{Cu}_{0.5} \mathrm{La}_{0.15} \mathrm{Fe}_{1.85} \mathrm{O}_{4}$ as manifested in Fig. 4(a-f). The STEM graphs, Fig. 4(a, c and e), demonstrate the nanocrystalline nature of all the samples. It is plainly noticed the STEM micrographs possess almost spherical crystallites which indiscriminately distributed throughout the ferrite sample surface.

Furthermore, CCL samples show agglomeration partly, which emanates from its constituents magnetic nature in addition to binding forces among surface nanoparticles. To corroborate the existence of the different metals in CCL ferrite samples, EDX micrographs were utilized to this mission as seen in Fig. 4(b, $\mathrm{d}$ and $\mathrm{f}$ ). Actually, the EDX charts of CCL powders affirmed existence of metal cations; La, Co, Fe, Cu and $O$ ions with no others traces of impurity; asserting the purity of CCL nanoferrite samples even substituted by a rare earth element (La). Furthermore La/Fe atomic percent matches with the desired ratios; affirmed from La peaks leveraging on account of iron; as in Fig. 4(d,f). Additionally, atomic\% ratio of $(\mathrm{Co}+\mathrm{Cu}) / \mathrm{Fe}$ and $(\mathrm{Co}+\mathrm{Cu}) /(\mathrm{Fe}+\mathrm{La})$ is just about 0.5 ; corroborating, once more, the prepared powders purity.

Furthermore, the characteristic mapping of $\mathrm{Co}_{0.5} \mathrm{Cu}_{0.5} \mathrm{La}_{0.15} \mathrm{Fe}_{1.85} \mathrm{O}_{4}$ nanoferrite, for instance, Fig. 5, which reveals the constituent elements homogeneous distribution.

\subsection{Magnetic properties}

\subsubsection{Magnetic parameters of CCL nanoferrites}

The hysteresis loops for the $\mathrm{Co}_{0.5} \mathrm{Cu}_{0.5} \mathrm{La}_{\mathrm{x}} \mathrm{Fe}_{2-\mathrm{x}} \mathrm{O}_{4}$ nanoferrites at room temperature $(\mathrm{RT}=303 \mathrm{~K})$, utilizing a field to $\pm 20 \mathrm{kOe}$, are illustrated in Fig. 6 . Then collected magnetic parameters; $M_{S}, M_{r}$ and $H_{C}$ of $C C L$ nanoferrites are tabulated in Table 1 . The $M_{S}$ values are steadily diminishing with further substitution of $\mathrm{La}^{3+}$ ion; from $\mathrm{M}_{\mathrm{S}}=53.67 \mathrm{emug}^{-1}$ (for $\mathrm{x}=0.0$ ) until $\mathrm{M}_{\mathrm{S}}=42.75 \mathrm{emug}^{-1}$ (for $\mathrm{x}=0.15$ ). In fact, $\mathrm{M}_{\mathrm{S}}$ values of ferrite materials are in straight proportionality with cations magnetic moment, which relies mainly on the unpaired (e) in the ferrite cations [24]. Hence, this progressively decrement in $M_{S}$ values is a logical result to the magnetic moment difference for $\mathrm{La} / \mathrm{Fe}$ cations, where $\mathrm{La}\left(2.78 \mu_{\mathrm{B}}\right)$ and $\mathrm{Fe}\left(5.92 \mu_{\mathrm{B}}\right)$; resulting deteriorating A-B super-exchange type [25]. Then remanent magnetizations of CCL nanoferrites introduce the identical trend as saturation magnetization, with the same dialectics, from 27.79 to $21.53 \mathrm{emug}^{-1}$; with further La substitution. 
Table 1

The lattice parameter $\left(a_{\text {exp }}\right)$, crystallite size $\left(D_{W-H}\right)$, saturation magnetization $\left(M_{s}\right)$, remanent magnetization $\left(\mathrm{M}_{\mathrm{r}}\right)$ and coercivity $\left(\mathrm{H}_{\mathrm{C}}\right)$ initial permeability $\left(\mu_{\mathrm{i}}\right)$, anisotropy constant $(K)$ and microwave frequency $\left(\omega_{M}\right)$ of CCL nanoferrites.

\begin{tabular}{|c|c|c|c|c|c|c|c|c|}
\hline$x$ & $\begin{array}{l}a_{\exp } \\
(\AA)\end{array}$ & $\begin{array}{l}D_{W-H} \\
(n m)\end{array}$ & $\begin{array}{l}M_{S} \\
(e m u / g)\end{array}$ & $\begin{array}{l}M_{r} \\
(e m u / g)\end{array}$ & $\begin{array}{l}\mathrm{H}_{\mathrm{C}} \\
(\mathrm{Oe})\end{array}$ & $\mu_{\mathrm{i}}$ & $\begin{array}{l}\mathrm{K} \\
\left(\mathrm{erg} / \mathrm{cm}^{3}\right)\end{array}$ & $\begin{array}{l}\omega_{M} \\
(\mathrm{GHz})\end{array}$ \\
\hline 0.0 & 8.375 & 20.94 & 53.67 & 27.79 & 1078.80 & 1.00 & 60311.66 & 11.87 \\
\hline 0.03 & 8.375 & 21.56 & 51.53 & 25.95 & 1044.40 & 1.02 & 56060.35 & 11.40 \\
\hline 0.06 & 8.330 & 25.58 & 51.07 & 26.03 & 957.73 & 1.31 & 50949.24 & 11.30 \\
\hline 0.09 & 8.330 & 33.01 & 50.57 & 25.46 & 922.19 & 1.74 & 48578.28 & 11.19 \\
\hline 0.12 & 8.327 & 30.27 & 43.86 & 22.03 & 1048.60 & 1.22 & 47907.91 & 9.70 \\
\hline 0.15 & 8.375 & 28.41 & 42.75 & 21.53 & 1111.30 & 1.05 & 49487.58 & 9.46 \\
\hline
\end{tabular}

Table 2

The kinetic rate constants $\left(k_{0}, k_{1}\right.$ and $\left.k_{2}\right)$ and correlation coefficient $\left(R^{2}\right)$ for zeroth, first and second order reaction kinetics of RhB dye with and without CCL photocatalyst nanoparticles.

\begin{tabular}{|llll|}
\hline Sample & \multicolumn{2}{l|}{ Kinetic model parameters } & \\
\cline { 2 - 4 } & Zeroth order & First order & Second order \\
\hline $\mathrm{RhB}$ & $\mathrm{k}_{0}=-1.23 \times 10^{-4}$ & $\mathrm{k}_{1}=1.76 \times 10^{-4}$ & $\mathrm{k}_{2}=2.52 \times 10^{-4}$ \\
& $\mathrm{R}^{2}=0.977$ & $\mathrm{R}^{2}=0.978$ & $\mathrm{R}^{2}=0.980$ \\
$\mathrm{RhB}+\mathrm{Co}_{0.5} \mathrm{Cu}_{0.5} \mathrm{Fe}_{2} \mathrm{O}_{4}$ & $\mathrm{k}_{0}=-9.11 \times 10^{-4}$ & $\mathrm{k}_{1}=0.00137$ & $\mathrm{k}_{2}=0.00207$ \\
& $\mathrm{R}^{2}=0.998$ & $\mathrm{R}^{2}=0.998$ & $\mathrm{R}^{2}=0.994$ \\
$\mathrm{RhB}+\mathrm{Co}_{0.5} \mathrm{Cu}_{0.5} \mathrm{Sm}_{0.09} \mathrm{Fe}_{1.91} \mathrm{O}_{4}$ & $\mathrm{k}_{0}=-0.00459$ & $\mathrm{k}_{1}=0.01498$ & $\mathrm{k}_{2}=0.08797$ \\
& $\mathrm{R}^{2}=0.995$ & $\mathrm{R}^{2}=0.868$ & $\mathrm{R}^{2}=0.587$ \\
\hline
\end{tabular}

For $\mathrm{H}_{\mathrm{C}}$ values, it possesses a distinct trend; firstly presents a downward one, from 1078.8 to $922.19 \mathrm{Oe}$ (for $0.0 \leq x \leq 0.09$ ), and an upward one from 922.19 to 1111.3 Oe (for $0.09 \leq x \leq 0.15$ ). This abnormal trend of $\mathrm{H}_{\mathrm{C}}$ for $\mathrm{CCL}$ nanoferrites can be argued as follow. Firstly, the introduction of the nonmagnetic $\mathrm{La}^{3+}$ ions in CCL nanoferrites and its accompanied impact is diminishing saturation magnetization; therefore, the field needed to clobber this magnetization property to 0 levels, also, is decreased. Secondly the $\mathrm{H}_{\mathrm{C}}$ behavior in the range $0.09 \leq x \leq 0.15$ has two reasoning. The first one is the CCL crystallite size impact; with its inversely proportional to coercivity [26]. As shown in Fig. 2, crystallite size of CCL nanoferrites in Loading [MathJax]/jax/output/CommonHTML/jax.js hent behavior. Hence, as the crystallite size diminishes as the 
grain boundaries augment, i.e., the disordered regions increase and required coercivity field, $\mathrm{H}_{\mathrm{C}}$, as a result increase. The second one is magneto-crystalline anisotropy of the substituted rare earth element (La) which increases the coercivity of the resultant ferrite. Actually, in materials containing heavy rare-earth elements, the spin-orbit coupling is strong. Once magnetized, a high field must be utilized to reverse the magnetization direction after conquer the anisotropy produced from this coupling [27]. Thus, with further La substitution, in the span $0.09 \leq x \leq 0.15$, spin-orbit coupling and consequently the magneto-crystalline anisotropy of $\mathrm{CCL}$ nanoferrites increase and hence $\mathrm{H}_{\mathrm{C}}$ value increases. At last, it is concluded that the $\mathrm{CCL}$ samples have hard magnetic features which can be adjusted by $\mathrm{La}^{3+}$ ions substitutions. Finally, the nanoferrite $\mathrm{Co}_{0.5} \mathrm{Cu}_{0.5} \mathrm{La}_{0.15} \mathrm{Fe}_{1.85} \mathrm{O}_{4}$ have a moderate saturation value $42.75 \mathrm{emu} / \mathrm{g}$ and the highest coercivity value $1111.3 \mathrm{Oe}$; candidate it to be an effective material for storage and recording applications.

Additionally, initial permeability and anisotropy constant of the $\mathrm{Co}_{0.5} \mathrm{Cu}_{0.5} \mathrm{La}_{x} \mathrm{Fe}_{2-\mathrm{x}} \mathrm{O}_{4}$ nanoferrites are calculated using the Ref. [28, 29], and tabulated in Table 1.

$$
\begin{aligned}
\text { Anisotropyconstant }(K) & =\frac{M_{S} \times H_{C}}{0.96} \\
\text { Initialpermeability }\left(\mu_{i}\right) & =\frac{M_{S}^{2} \times D_{W-H}}{K}
\end{aligned}
$$

In fact, initial permeability has a distinctive attitude with La/Fe substitution process; increasing behavior for the nanoferrites with $0.00 \leq x \leq 0.09$ and a decreasing one for $x=0.12$ and 0.15 nanoferrites. Although, saturation magnetization has a regular decrement behavior, $\mu_{i}$ introduces this abnormal demeanor. Indeed the impact of crystallite size and anisotropy constant are decision makers for $\mu_{i}$ behavior. Thus La substitution in Co-Cu nanoferrites, in the range $0.00 \leq x \leq 0.09$, supports magnetic flux to pass and concentrate within these nanoferrites and inhibit it for $\mathrm{x}=0.12$ and 0.15 nanoferrites. Contrary to expected results anisotropy constant introduces a decrement behavior with $\mathrm{La} / \mathrm{Fe}$ substitution process. Where, it was expected that the spin-orbital coupling of La ions can enhance anisotropy property of these nanoferrites.

\subsubsection{High frequency response of CCL ferrite nanoparticles}

Basically, ferrite materials are the only ones available for microwave realm applications. Where for frequency $(1 \mathrm{GHz} \leq \mathrm{f} \leq 1000 \mathrm{GHz}$ ), the electrical energy is not transported via wires, but through electromagnetic waves which contained in wave-guides and transmitted through space. So we have to investigate the high frequency response of the prepared CCL nanoferrites to discover their applications in microwave fields. The microwave frequency $\left(\omega_{M}\right)$ values for all CCL nanoparticles are determined using Ref. [30] and then saved in Table 1. From the calculated $\omega_{\mathrm{M}}$ values, $11.87 \mathrm{GHz}-9.46 \mathrm{GHz}, \mathrm{CCL}$ nanoferrites may be employing in high frequency applications. These values introduce a significant progress compared with other systems containing different rare earth elements with maximum $\omega_{M}$ value $84 \mathrm{GH} 7[31]$ 


\subsubsection{Switching field distributions (SFD) response of CCL ferrite nanoparticles}

Figure 7, with its inset curve, shows the SFD plots (dM/dH vs. H) of all CCL nanoferrites. Physically, SFD plots scout the constituting cations exchange coupling. All SFD curves acquire higher values at large reverse field meanwhile introduce an almost constant one for higher fields; affirming the vigorous cations exchanges at higher reverse filed. Then inset plot, for large reverse field; confirming those figures are discontinuous. Analogous behavior was declared regarding different ferrites containing diverse rare earth elements [31].

\subsection{Dielectric properties}

Regarding to dielectric bounds of La- substituted Co-Cu ferrite nanoparticles, special studies have been investigated. Actually, in frequency span $\left(50 \mathrm{~Hz}-5 \mathrm{MHz}\right.$ at RT), dielectric parameters (dielectric constant, $\varepsilon^{\prime}$, and loss tangent, tan $\delta$ ) besides conductivity $\left(\sigma_{\mathrm{ac}}\right)$ for the synthesized system of $\mathrm{Co}_{0.5} \mathrm{Cu}_{0.5} \mathrm{La}_{\mathrm{x}} \mathrm{Fe}_{2-\mathrm{x}} \mathrm{O}_{4}$ nanoparticles have been studied. Fundamentally, $\varepsilon^{\prime}$ refers to the amount of stored energy in the ferrite material, whereas tan $\delta$ gives the energy loss out of phase rather than the response of the material, whilst $\sigma_{\mathrm{ac}}$, determines the kind and mechanization of conduction within an applied field. Actually, the $\varepsilon^{\prime}$ and $\sigma_{\mathrm{ac}}$ results of $\mathrm{Co}_{0.5} \mathrm{Cu}_{0.5} \mathrm{La}_{\mathrm{x}} \mathrm{Fe}_{2-\mathrm{x}} \mathrm{O}_{4}$ samples are determined using the Ref. [32], whilst tan $\delta$ result is getting directly from the instrument. As noticed in Fig. 8(a) $\varepsilon^{\prime}$ decreases more speedily in the frequency then becomes dormant as frequency augment; which is the typical demeanor of all ferrite [33]. Based on Koop's model, any ferrite structure formed by arrangement of conducting regions (grains) estranged with lower conducting regions (grain boundaries) [34]. Hence at lower frEq. region various charge carriers transfer among dissimilar ions of the same element, e.g., $\mathrm{Fe}^{2+} \& \mathrm{Fe}^{3+}$, which accumulate on grain boundaries (GBs); due to it high resistivity. This phenomenon is called Maxwell-Wagner (M-W) polarization which gives a high value of dielectric constant which decreases slowly with frequency [35]. At higher frEq. these charges within grains itself cannot pursue the frequency of the applicable field, and then polarization diminishing and almost stable $\varepsilon^{\prime}$ level is obtained [36]. As observed from inset curve of Fig. 8(a), the dielectric constant of CCL nanoferrites decrease gradually with further $\mathrm{La}^{3+}$ substitution in view of two respects. The first one is the electron hopping among $\mathrm{Fe}^{2+} \& \mathrm{Fe}^{3+}$ ions reduces by $\mathrm{La}^{3+} / \mathrm{Fe}^{3+}$ ions replacement. The second is account for the increment of resistivity, originated from $3 \mathrm{~d}-4 \mathrm{f}$ coupling of La ions, where the relation between resistivity and $\varepsilon^{\prime}$ is inversely proportion [37].

As for the $\sigma_{a c}$ behavior, it has a growing attitude with frequency; see Fig. 8(b). Many workers declared that presence similarity for $\sigma_{\mathrm{ac}}$ and $\varepsilon^{\prime}$ mechanisms for ferrite materials [38-40]. Consequently, the preceding interpretation of $\varepsilon^{\prime}$ for $\mathrm{CCL}$ nanoferrites is benefit for understanding $\sigma_{\mathrm{ac}}$ behavior with frequency. Hence, as noticed from the inset curve of Fig. 8(b), $\sigma_{a c}$ decreases with the augment in La content. As for conductivity frequency dependence, the crowd of charges on CCL nanoferrites GBs is the major cause for the independent regime in $\sigma_{\mathrm{ac}}$ plot. By increasing frequency, the impact of interior Gs of CCL nanoferrites

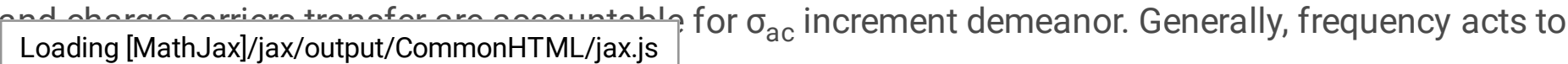


augment the conduction phenomenon by its propelling diverse charge carriers between the conduction positions [41].

The tan $\delta$ of the investigated CCL ferrite nanoparticles is given in Fig. 8(c). In fact, the decreases in tan $\delta$ value are noticed with further increasing frequency and with $\mathrm{La}^{3+}$ ions substitution; see the inset curve of Fig. 8(c). This behavior of tan $\delta$ can be justified using two facts. With increasing La content in CCL nanoferrites, polarization $\left(\varepsilon^{\prime}\right)$ depressed and also the accompanied loss decrease; this is the first reason. The other cause for tan $\delta$ behavior is the CCL crystallite size by it's inversely proportion with it [42].

\subsection{Optical studies}

\subsubsection{UV-Visible absorption and optical energy gap}

For the present $\mathrm{Co}_{0.5} \mathrm{Cu}_{0.5} \mathrm{La}_{x} \mathrm{Fe}_{2-x} \mathrm{O}_{4} ;(x=0.0,0.03,0.06,0.09,0.12,0.15)$ ferrite nanoparticles, one can notice a broad absorption band positioned nearly at $500 \mathrm{~nm}$; as shown in Fig. 9. Generally, ferrite materials are opaque at wavelengths $\leq 200 \mathrm{~nm}$; at which the photon energy is $\geq$ optical band gap $\left(E_{g}\right)$, which is required for transition from valence to conduction bands [43]. The $E_{g}$ values of $\mathrm{Co}_{0.5} \mathrm{Cu}_{0.5} \mathrm{La}_{\mathrm{x}} \mathrm{Fe}_{2-\mathrm{x}} \mathrm{O}_{4}$ nanoferrites can be calculated by extrapolating the linear portion curve of (ahv $)^{2} \mathrm{vs}$. photon energy (hv) to (ahv) ${ }^{2}=0$; for direct allowed transition (Tauc's plot) (Fig. 10(a-f)) [44]. From Tauc's plot, $E_{g}$ values of $C C L$ nanoferrites are determined. Basically, the band gap can be tuned based on several factors: e.g., crystallite size, structural parameter and impurities. The calculated $E_{g}$ values of $C C L$ nanoferrites are displayed in Fig. 11. In fact our energy gap possesses a peculiar demeanor; a red shift from $3.04 \mathrm{eV}$ to $2.46 \mathrm{eV}$ (for $0.0 \leq \mathrm{x} \leq 0.09$ ) and a blue shift from $2.46 \mathrm{eV}$ to $2.98 \mathrm{eV}$ for $(0.09 \leq \mathrm{x} \leq 0.15$ ). A similar $E_{g}$ behavior was observed in an earlier work for $\mathrm{Zn}-\mathrm{Mg}$ nanoferrites [13]. This behavior of $E_{g}$ can be explained trough two scenarios. Firstly, further La content generates a lot of donor levels in the forbidden band, producing $E_{g}$ decrement. Secondly, this tendency of $E_{g}$ may be accredited to the decrement attitude of CCL nanoferrites crystallite size in the range $0.09 \leq x \leq 0.15$ (see Fig. 2); where the relationship between the band gap and particle size is an inversely one [15]. Also the augmentation of conductivity of Co-Cu nanoferrites with further $\mathrm{La}^{3+}$ substituting confirms the $\mathrm{E}_{\mathrm{g}}$ behavior in that range.

\subsubsection{Photocatalytic activity}

The influence of $\mathrm{Co}_{0.5} \mathrm{Cu}_{0.5} \mathrm{La}_{\mathrm{x}} \mathrm{Fe}_{2-\mathrm{x}} \mathrm{O}_{4}$ nanoferrites on photo-catalytic dye degradation of Rhodamine $\mathrm{B}$ $(\mathrm{RhB})$ was investigated using absorption spectra. However, the $\mathrm{E}_{\mathrm{g}}$ of photocatalyst governs the absorbed wavelength and produces electron-hole pairs. The nanoferrite specimens with $\mathrm{x}=0.0$ and $0.09 \mathrm{La}^{3+}$ were chosen for this investigation because $x=0.0$ represent the pristine ferrite and $x=0.09$ has the least $E_{g}$ value. This choice based on the opposite relation between $E_{g}$ and photodegradation behavior [13]. Moreover, the replacement of rare earth cations in Co-Cu ferrite gives good optical absorption in visible range point toward enhanced photodegradation efficiency. As a consequence of metastable La- $4 \mathrm{f}$ energy levels creation near the lower edge of the conduction band of Co-Cu ferrite, this indicates the decrease in 
the band gap. A further factor is the defects resulting from La doping which act as trapping centers and simplify the split-up of photogenerated electron-hole pairs and increase the life time of charge carrier [45].

The photo-catalytic degradation efficiency is obtained from the variation in Absorbance for the reason of direct relation between concentration (C) and absorbance (A) [46]. It is well known that, the selfdegradation efficiency of $\mathrm{RhB}$ (without catalyst) is very small value for dye disposal [13]. Figure 12(a-c) manifests photocatalytic degradation of $\mathrm{RhB}$ and $\mathrm{RhB}+\mathrm{Co}_{0.5} \mathrm{Cu}_{0.5} \mathrm{La}_{\mathrm{x}} \mathrm{Fe}_{2-\mathrm{x}} \mathrm{O}_{4}(\mathrm{x}=0.0$, and 0.09) irradiated under solar light at variable times (from 0-180 min). The reduction in absorbance intensity designates enhancement in dye degradation. The mechanism for $\mathrm{RhB}$ photodegradation of the nanoferrite in which $\mathrm{x}=0.9 \mathrm{La}$ (as an example) is understood with aid of some of free radicals. All the spectra evident the characteristic absorption curves of $\mathrm{RhB}$ with a peak, at $\sim 552 \mathrm{~nm}$ and a shoulder at $~$ $512 \mathrm{~nm}[47]$.

The \% degradation of samples is determined via the equation listed in Ref. [48]. Figure 13 illustrates \% degradation for pure RhB and RhB over CCL nanoferrites with $(x=0.0$ and 0.09$)$. The $\%$ degradation, after irradiation for $180 \mathrm{~min}$, of pure $\mathrm{RhB}$ dye is just $3.31 \%$; which is an unsatisfactory impact. As for the \% degradation for RhB over CCL nanoferrites with $(x=0.0$ and 0.09$)$ photocatalysts is enlarged; $(22.37 \%$ and $94.50 \%$, respectively). Hence, the catalytic recital was enhanced with $\mathrm{La} / \mathrm{Fe}$ substitution process via the next most probable discussion. When the electrons were excited from valence band (VB) to created energy level CCL conduction band (CB) in the sample under sunlight irradiation, the photogenerated holes in VB react with surface water or hydroxyl ion to yield $\mathrm{OH}^{\bullet}$ radical, which is a good oxidant in the degradation of RhB and instantaneously, electrons in the $\mathrm{CB}$ reacts with adsorbed oxygen molecule to yield $\mathrm{O}_{2}{ }^{-}$. Moreover, it combines with $\mathrm{H}^{+}$to yield $\mathrm{HO}_{2}$. [49], which react with trapped electrons to yield $\mathrm{OH}^{\bullet}$ [50]. It is obvious that, $\mathrm{OH}^{\bullet}, \mathrm{HO}_{2}, \mathrm{O}_{2}{ }^{-}$and $h_{V B}^{+}$are active species included in $\mathrm{RhB}$ photodegredation. Regarding the previous argument, the photochemical reaction for the degradation of $\mathrm{RhB}$ under sunlight irradiation of Co-Cu-La ferrite photocatalyst was summarized as follows [13].

$$
\begin{aligned}
& \mathrm{Co}_{0.5} \mathrm{Cu}_{0.5} \mathrm{La}_{0.09} \mathrm{Fe}_{1.91} \mathrm{O}_{4}+h v \rightarrow \mathrm{Co}_{0.5} \mathrm{Cu}_{0.5} \mathrm{La}_{0.09}-\mathrm{Fe}_{1.91} \mathrm{O}_{4}+\left(e^{-} \text {and } h^{+}\right) \\
& e^{-}+\mathrm{O}_{2} \rightarrow \mathrm{O}_{2}^{-} \\
& h^{+}+\mathrm{HO}_{2} \rightarrow \mathrm{H}^{+}+\mathrm{OH}^{\bullet} \\
& \mathrm{O}_{2}^{-}+\mathrm{H}^{+} \rightarrow \mathrm{HO}_{2} \cdot{ }^{-} 2 e^{-}+\mathrm{HO}_{2}+\mathrm{H}^{+} \rightarrow \mathrm{OH}^{\bullet}+\mathrm{OH}^{-} \text {and } h^{+}+\mathrm{OH}^{-} . \rightarrow \mathrm{OH}^{\bullet}
\end{aligned}
$$$$
\mathrm{OH}^{\bullet}, \mathrm{HO}_{2}, \mathrm{O}_{2}^{-}, h_{V B}^{+}+\mathrm{RhB} \rightarrow \text { Degradedproducts }
$$

These radicals, formed from the previous steps, can interact with the toxic $\mathrm{RhB}$ dyes, converting its complex molecules to simple and non-toxic ones. Dhiman et al. [51] in previous work obtain comparable mechanisms for photocatalytic behaviors for $\mathrm{CoFe}_{2} \mathrm{O}_{4}$ ferrite doped with various rare earths. 
To distinguish the photocatalytic activity protocol of CCL photocatalyst, the three kinetic models (0th, 1st and 2nd orders) are determined using the following equations [52].

$$
A_{t}=A_{o}-k_{o} t, A_{t}=A_{o} e^{-k_{1} t}, \frac{1}{A_{t}}=\frac{1}{A_{o}}+k_{2} t
$$

where $A_{t}$ and $A_{o}$ are absorbance of RhB dye after and before irradiation time $(t)$, respectively. For this mission, the plots of $A_{t}, \ln \left(A_{o} / A\right)$ and $1 / A_{t}$ versus time are determined with their linear fitting; see Fig. $14(\mathrm{a}-\mathrm{c})$. The three kinetic constants $\left(\mathrm{k}_{0}, \mathrm{k}_{1}\right.$ and $\left.\mathrm{k}_{2}\right)$ of zeroth, first and second order reaction kinetics, respectively of $\mathrm{RhB}$ and $(\mathrm{RhB}+\mathrm{CCL}$ samples $(\mathrm{x}=0.0$ and 0.09$)$ are calculated and tabulated in Table 2 . Also, correlation coefficient $\left(\mathrm{R}^{2}\right)$ of each order kinetic is calculated and inserted in Table 2 . The second order is the most favorable model for pure $R h B$, where its $R^{2}$ value is 0.980 (the highest value compared with other orders). As for RhB over CCL sample with $(x=0.0)$ has $\mathrm{R}^{2}$ value 0.998 for both zeroth and firstorders; declaring that these models are favorable models for degradation. Meanwhile for RhB over CCL sample with $(x=0.09)$ has $R^{2}$ value 0.995 for zeroth; demonstrating this model is the most suitable model for degradation of this sample. Finally, the $k_{0}, k_{1}$ and $k_{2}$ values for $\mathrm{RhB}$ dye degradations in presence of $\mathrm{CCL}$ nanoferrite powders are higher than those of pristine RhB dye; see Table 2. These outcomes confirm the CCL nanoferrites are capable of enhancing the RhB dye degradation efficiency in industrial community.

\section{Conclusion}

A sequence of lanthanum substituted cobalt-copper $\left(\mathrm{CO}_{0.5} \mathrm{Cu}_{0.5} \mathrm{La}_{x} \mathrm{Fe}_{2-\mathrm{x}} \mathrm{O}_{4} ; 0 \mathrm{x} \leq 0.15\right)(\mathrm{CCL})$ were prepared via a combustion approach. XRD charts of CCL samples affirmed the spinel structure for the prepared powders. Although the substitution process is a larger ion, $\mathrm{La}^{3+}(1.032 \AA)$, instead of a smaller one, $\mathrm{Fe}^{3+}$ $(0.645 \AA)$, the lattice parameter did not introduce an increment behavior. It has a peculiar trend; decrement from $(8.375 \AA$ at $x=0.0)$ to $(8.327 \AA$ at $x=0.12)$ then augment for the nanoferrite with $x=0.15$ to $8.375 \AA$. The crystallite size of CCL nanoferrites introduces a distinctive trend; increment from $(20.94 \mathrm{~nm}$ at $\mathrm{x}=0.0)$ to $(33.01 \mathrm{~nm}$ at $\mathrm{x}=0.09)$ then decrease step forward for $\mathrm{x}=0.12$ and 0.15 to $30.27 \mathrm{~nm}$ and $28.41 \mathrm{~nm}$, respectively. STEM micrographs possess almost spherical crystallites which indiscriminately distributed throughout the ferrite sample surface. $\mathrm{M}_{\mathrm{S}}$ values are steadily diminishing with further substitution of $\mathrm{La}^{3+}$ ion; from $M_{S}=53.67$ emug $^{-1}$ (for $\left.x=0.0\right)$ to $M_{S}=42.75$ emug $^{-1}$ at $(x=0.15) . H_{C}$ values, it possesses a distinct trend; firstly presents a downward one, from 1078.8 to 922.19 Oe (for $0.0 \leq x \leq 0.09$ ), and an upward one from 922.19 to 1111.3 Oe (for $0.09 \leq x \leq 0.15$ ). Dielectric constant and loss tangent have a decrement behavior with frequency and with substitution of La ions. $E_{g}$ has a peculiar demeanor; a red shift from $3.04 \mathrm{eV}$ to $2.46 \mathrm{eV}$ (for $0.0 \leq x \leq 0.09$ ) and a blue shift from $2.46 \mathrm{eV}$ to $2.98 \mathrm{eV}$ for $(0.09 \leq x \leq 0.15)$. The \% degradation for RhB over CCL nanoferrites with ( $x=0.0$ and 0.09$)$ photocatalysts is enlarged; (22.37\% and $94.50 \%$, respectively). The nanoferrite $\mathrm{Co}_{0.5} \mathrm{Cu}_{0.5} \mathrm{La}_{0.15} \mathrm{Fe}_{1.85} \mathrm{O}_{4}$ has a moderate saturation magnetization, highest coercivity and lowest loss which can be a suitable candidate for data 
storage applications. Moreover, $\mathrm{Co}_{0.5} \mathrm{Cu}_{0.5} \mathrm{La}_{0.15} \mathrm{Fe}_{1.85} \mathrm{O}_{4}$ can be utilized as a photocatalyst for $\mathrm{RhB}$ effluents removal with degradation efficiency $94.50 \%$ at $180 \mathrm{~min}$.

\section{Declarations}

\section{Acknowledgements}

"This research work was funded by Institutional Fund Projects under grant no. (IFPHI-165-247-2020). Therefore, authors gratefully acknowledge technical and financial support from the Ministry of Education and King Abdulaziz University, DSR, Jeddah, Saudi Arabia".

\section{References}

1. Mansour SF, Wageh S, Al-Wafi R, Abdo MA (2021) Enhanced magnetic, dielectric properties and photocatalytic activity of J Mater Sci: Mater Electron doped Mg-Zn ferrite nanoparticles by virtue of $\mathrm{Sm}^{3+}$ role. J Alloys Compd 856:157437

2. AlSalka Y, Granone LI, Ramadan W, Hakki A, Dillert R, Bahnemann DW (2019) Iron based photocatalytic and photoelectrocatalytic nano-structures: Facts, perspectives, and expectations. Appl Catal B Environ 244:1065-1095

3. Karakas IH (2021) The effects of fuel type onto the structural, morphological, magnetic and photocatalytic properties of nanoparticles in the synthesis of cobalt ferrite nanoparticles with microwave assisted combustion method. Ceram Int 47:5597-5609

4. Jadhav SA, Khedkar MV, Andhare DD, Gopale SB, Jadhav KM (2021) Visible light photocatalytic activity of magnetically diluted $\mathrm{Ni}-\mathrm{Zn}$ spinel ferrite for active degradation of rhodamine $\mathrm{B}$. Ceram Int 10:13980-13993

5. Kefeni KK, Mamba BB (2020) Photocatalytic application of spinel ferrite nanoparticles and nanocomposites in wastewater treatment. Review Sustainable Materials Technologies 23:e00140

6. Mansour SF, Al-Hazmi F, Abdo MA (2019) Relaxation time enhancement of cobalt zinc nanoferrites via $\mathrm{Cr}^{3+}$ doping. J Alloy Comp 792:626-637

7. Dojcinovic MP, Vasiljevic ZZ, Pavlovic VP, Barisic D, Pajic D, Tadic NB, Nikolic MV (2021) Mixed MgeCo spinel ferrites: Structure, morphology, magnetic and photocatalytic properties. J Alloys Compd 855:157429

8. Spaldin NA, Magnetic materials: fundamentals and applications, Cambridge university press (2010)

9. More DS, Helavi VB, Kulkarni SB, Patankar KK, Comparative study on structural and magnetic characterization of Co-Cu-Zn ferrites prepared by different sintering routes, Materials Today: Proceedings 23 (2020) 338-344

10. Rashmi ShK, Naik HSB, Jayadevappa H, Sudhamani ChN, Patil SB, Naik MM (2017) Influence of $\mathrm{Sm}^{3+}$ ions on structural, optical and solar light driven photocatalytic activity of spinel $\mathrm{MnFe}_{2} \mathrm{O}_{4}$ 
11. Nag S, Roychowdhury A, Das D, Das S, Mukherjee S (2018) Structural and magnetic properties of erbium $\left(\mathrm{Er}^{3+}\right)$ doped nickel zinc ferrite prepared by sol-gel autocombustion method. J Magn Magn Mater 466:172-179

12. Hashim M, Raghasudha M, Meena SS, Shah J, Shirsath SE, Kumar S, Ravinder D, Bhatt P, Kumar R, Kotnala RK (2018) Influence of rare earth ion doping (Ce and Dy) on electrical and magnetic properties of cobalt ferrites. J Magn Magn Mater 449:319-327

13. Mansour SF, Al-Wafi R, Abdo MA (2020) Zn-Mg-La nanoferrites for storage and high frequency devices with augmenting the photocatalytic performance. J Alloy Compd 826:154125

14. Mansour SF, Abdo MA, Kzar FL (2018) Effect of Cr dopant on the structural, magnetic and dielectric properties of Cu-Zn nanoferrites. J Magn Magn Mater 465:176-185

15. Abdo MA, El-Daly AA (2021) Sm-substituted copper-cobalt ferrite nanoparticles: Preparation and assessment of structural, magnetic and photocatalytic properties for wastewater treatment applications. J Alloy Compd 883:160796

16. Mansour SF, Abdo MA, El-Dek SI (2017) Improvement of physico-mechanical properties of Mg-Zn nanoferrites via $\mathrm{Cr}^{3+}$ doping. J Magn Magn Mater 422:105-111

17. Shannon RD (1976) Revised effective ionic radii and systematic studies of interatomic distances in halides and chalcogenides. Acta Crystallogr Sect A 32:751-767

18. Mansour SF, Hemeda OM, El-Dek SI, Salem BI (2016) Influence of La doping and synthesis method on the properties of $\mathrm{CoFe}_{2} \mathrm{O}_{4}$ nanocrystals. J Magn Magn Mater 420:7-18

19. Hashim M, Raghasudha M, Meena SS, Shah J, Shirsath SE, Kumar S, Ravinder D, Bhatt P, Alimuddin R, Kumar RK, Kotnala (2018) Influence of rare earth ion doping (Ce and Dy) on electrical and magnetic properties of cobalt ferrites. J Magn Magn Mater 449:319-327

20. Mariosi FR, Venturini J, da Cas Viegas A, Bergmann CP (2020) Lanthanum-doped spinel cobalt ferrite $\left(\mathrm{CoFe}_{2} \mathrm{O}_{4}\right)$ nanoparticles for environmental applications. Ceram Int 46:2772-2779

21. Dasent WE (1982) Inorganic Energetics: An Introduction, 2nd edn. Cambridge University Press

22. Ounacer M, Rabi B, Essoumhi A, Sajieddine M, Costa BFO, Emo M, Razouk A, Sahlaoui M (2021) Influence of $\mathrm{Al}^{3+}$ substituted cobalt nano-ferrite on structural, morphological and magnetic properties. J Alloys Compd 854:156968

23. Imanipour P, Hasani S, Afshari M, Sheykh S, Seifoddini A, Jahanbani-Ardakani Kh (2020) The effect of divalent ions of zinc and strontium substitution on the structural and magnetic properties on the cobalt site in cobalt ferrite. J Magn Magn Mater 510:166941

24. Ankita Goyal S, Kapoor P, Samuel V, Kumar S, Singhal (2015) Facile protocol for reduction of nitroarenes using magnetically recoverable $\mathrm{CoM}_{0.2} \mathrm{Fe}_{1.8} \mathrm{O}_{4}(\mathrm{M}=\mathrm{Co}, \mathrm{Ni}, \mathrm{Cu}$ and $\mathrm{Zn})$ ferrite nanocatalysts. RSC Adv 5:51347

25. Ghosh MP, Mukherjee S (2019) Disordered surface spins induced large exchange anisotropy in single-phase $\mathrm{Sm}^{3+}$ ions substituted nickel ferrite nanoparticles. J Magn Magn Mater 489:165320 
26. Sonia Gaba A, Kumar PS, Rana M, Arora (2018) Influence of $\mathrm{La}^{3+}$ ion doping on physical properties of magnesium nanoferrites for microwave absorption application. J Magn Magn Mater 460:69-77

27. Goldman A, Modern ferrite technology, Springer Science \& Business Media (2006)

28. Akhtar MN, Yousaf M, Khan SN, Nazir MS, Ahmad M, Khan MA (2017) Structural and electromagnetic evaluations of $\mathrm{YIG}$ rare earth doped $(\mathrm{Gd}, \mathrm{Pr}, \mathrm{Ho}, \mathrm{Yb})$ nanoferrites for high frequency. Ceram Int 43:17032-17040

29. Harzali H, Marzouki A, Saida F, Megriche A, Mgaidi A (2018) Structural, magnetic and optical properties of nanosized $\mathrm{Ni}_{0.4} \mathrm{Cu}_{0.2} \mathrm{Zn}_{0.4} \mathrm{R}_{0.05} \mathrm{Fe}_{1.95} \mathrm{O}_{4}\left(\mathrm{R}=\mathrm{Eu}^{3+}, \mathrm{Sm}^{3+}, \mathrm{Gd}^{3+}\right.$ and $\left.\mathrm{Pr}^{3+}\right)$ ferrites synthesized by co-precipitation method with ultrasound irradiation. J Magn Magn Mater 460:89-94

30. Akhtar MN, Khan AA, Akhtar MN, Ahmad M, Khan MA (2019) Structural Rietveld refinement, morphological and magnetic features of $\mathrm{Cu}$ doped $\mathrm{Co}$ Ce nanocrystalline ferrites for high frequency applications. Physica B: Phys Condens Matter 561:121-131

31. Akhtar MN, Siddiq HA, Nazir MS, Khan MA (2020) Preparations and tailoring of structural, magnetic properties of rare earths (REs) doped nanoferrites for microwave high frequency applications. Ceram Int 46:26521-26529

32. Mansour SF, Abdo MA, Alwan SM (2018) The role of $\mathrm{Cr}^{3+}$ ions substitution on structural, magnetic and dielectric modulus of manganese zinc nanoferrites. Ceram Int 44:8035-8042

33. Mansour SF, Dawood A, Abdo MA (2019) Enhanced magnetic and dielectric properties of doped CoZn ferrite nanoparticles by virtue of $\mathrm{Cr}^{3+}$ role. J Mater Sci: Mater Electron 30:17262-17275

34. Mansour SF, Ahmed MA, El-Dek SI, Abdo MA, Kora HH (2017) Enhancement of the physical properties of novel (1-x) $\mathrm{NiFe}_{2} \mathrm{O}_{4}+(\mathrm{x}) \mathrm{Al}_{2} \mathrm{O}_{3}$ nanocomposite. Appl Phys A 123:480

35. Ahmed MA, Mansour SF, Abdo MA (2012) Electrical properties of Cu substituted Co nano ferrite. Phys Scr 86:025705-025713

36. Ahmed MA, Mansour SF, Abdo MA (2013) Improvement of the physical properties of novel (1-y) $\mathrm{Co}_{0.8} \mathrm{Cu}_{0.2} \mathrm{Fe}_{2} \mathrm{O}_{4}+(\mathrm{y}) \mathrm{SrTiO}_{3}$ nanocomposite. Mater Res Bull 48:1796-1805

37. Vinosha PA, Manikandan A, Ragu R et al (2021) Impact of nickel substitution on structure, magnetooptical, electrical and acoustical properties of cobalt ferrite nanoparticles. J Alloys Compd 857:157517

38. Mansour SF, Zaher H, Al-Wafi R, Almossalami HA, Abdo MA (2021) Tuning of structural, magnetic and dielectric properties of $\mathrm{M}_{0.45} \mathrm{La}_{0.10} \mathrm{Fe}_{2.45} \mathrm{O}_{4} ;(\mathrm{M}=\mathrm{Mn}, \mathrm{Co}, \mathrm{Cu}, \mathrm{Mg}$ and $\mathrm{Zn})$ nanoparticles: effect of particle size and porosity. J Mater Sci: Mater Electron 32:1-18

39. Mansour SF, Karamany MM, Al-Wafi R, El-Dek SI, Almossalami HA, Abdo MA (2021) The effective role of diamagnetic $\mathrm{Pb}$ ions in tailoring the magnetic and dielectric properties of $\mathrm{BiFeO}_{3}$ nanomultiferroic. J Mater Sci: Mater Electron 32:3621-3637

40. Mansour SF, Hemeda OM, Abdo MA, Nada WA (2018) Improvement on the magnetic and dielectric behavior of hard/soft ferrite nanocomposites. J Mol Struct 1152:207-214 
41. Mansour SF, Abdo MA (2017) Electrical modulus and dielectric behavior of $\mathrm{Cr}^{3+}$ substituted $\mathrm{Mg}-\mathrm{Zn}$ nanoferrites. J Magn Magn Mater 428:300-305

42. Ashtar M, Gong GS, Gao YX, Xu LM, Marwat MA, Wang YQ, Yuan SL, Tian ZM (2019) Synthesis, structural, electrical and magnetic properties of $\mathrm{Bi}_{2} \mathrm{Fe}_{4-x} \mathrm{Ga}_{x} \mathrm{O}_{9}(0 \leq \mathrm{x} \leq 1.6)$, Ceram. Int 45:1023610242

43. Abdo MA, Basfer NM, Sadeq MS (2021) The structure, correlated vibrations, optical parameters and metallization criterion of $\mathrm{Mn}-\mathrm{Zn}-\mathrm{Cr}$ nanoferrites. J Mater Sci: Mater Electron 32:15814-15825

44. Sadeq MS, Abdo MA (2021) Effect of iron oxide on the structural and optical properties of aluminoborate glasses. Ceram Int 47:2043-2049

45. Hu Z, Chen D, Wang S, Zhang N, Qin L, Huang Y (2017) Facile synthesis of Sm-doped BiFeO3 nanoparticles for enhanced visible light photocatalytic performance. Mater Sci Eng B 220:1-12

46. Sharma R, Thakur P, Kumar M, Sharma P, Sharma V (2018) Nanomaterials for high frequency device and photocatalytic applications: Mg-Zn-Ni ferrites. J Alloy Comp 746:532-539

47. Shankar K, Rashmi HSeethyaB, Naik H, Jayadevappa CN, Sudhamani SB, Patil (2017) Manjyanaik Madhukara Naik, Influence of $\mathrm{Sm}^{3+}$ ions on structural, optical and solar light driven photocatalytic activity of spinel $\mathrm{MnFe}_{2} \mathrm{O}_{4}$ nanoparticles. J Solid State Chem 255:178-192

48. Vijayaraghavan $T$, Suriyaraj SP, Selvakumar R, Venkateswaran R, Ashok A (2016) Rapid and efficient visible light photocatalytic dye degradation using $\mathrm{AFe}_{2} \mathrm{O}_{4}(\mathrm{~A}=\mathrm{Ba}, \mathrm{Ca}$ and $\mathrm{Sr})$ complex oxides. Mater Sci Eng B 210:43-50

49. Ma Y, Lu N, Lu Y, Guan JN, Qu J, Liu HY, Cong Q, Yuan X (2016) Comparative study of carbon materials synthesized "Greenly" for 2-CP removal. Sci Rep 9:29167

50. Kaneco S, Rahman MA, Suzuki T, Katsumata H, Ohta K (2004) Optimization of solar photocatalytic degradation conditions of bisphenol $A$ in water using titanium dioxide. J Photochem Photobiol A 163:419-424

51. Liu D, Liu Y, Wu Z, Tian F, Ye B, Chen X (2016) Enhancement of photodegradation of Ce, N, and P tridoped TiO by microwave radiation with visible light response for naphthalene. J Taiwan Inst Chem $\mathrm{E}$ 68:506-513

52. Aref AA, Qahtan S, Husain A, Somvanshi W, Khan YK, Manea (2020) J Mater Sci: Mater Electron 31:9335-9351

\section{Figures}




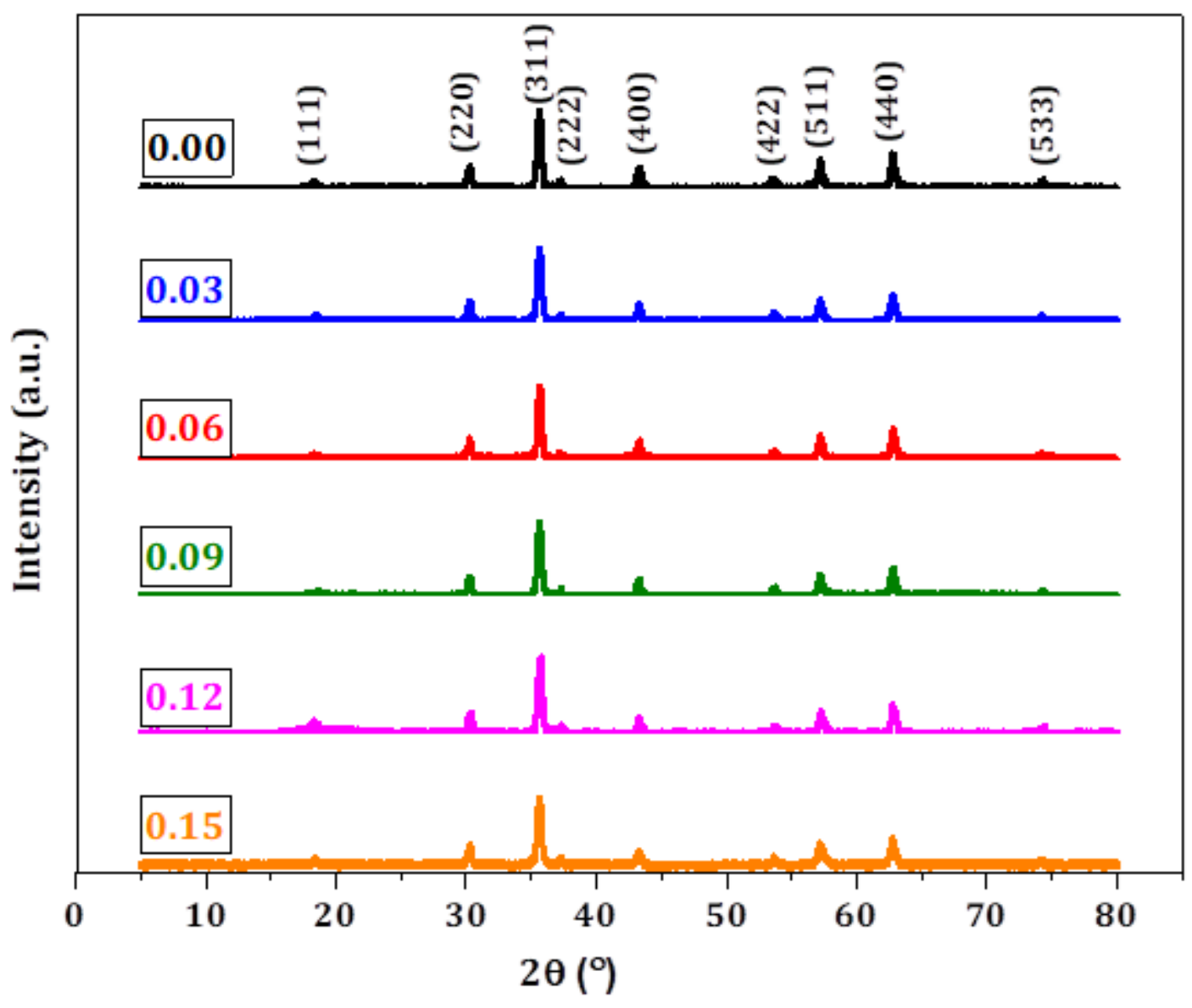

Figure 1

XRD difractograms of Co0.5Cu0.5LaxFe2-xO4; $(0.0 \leq x \leq 0.15)$ nanoferrites.

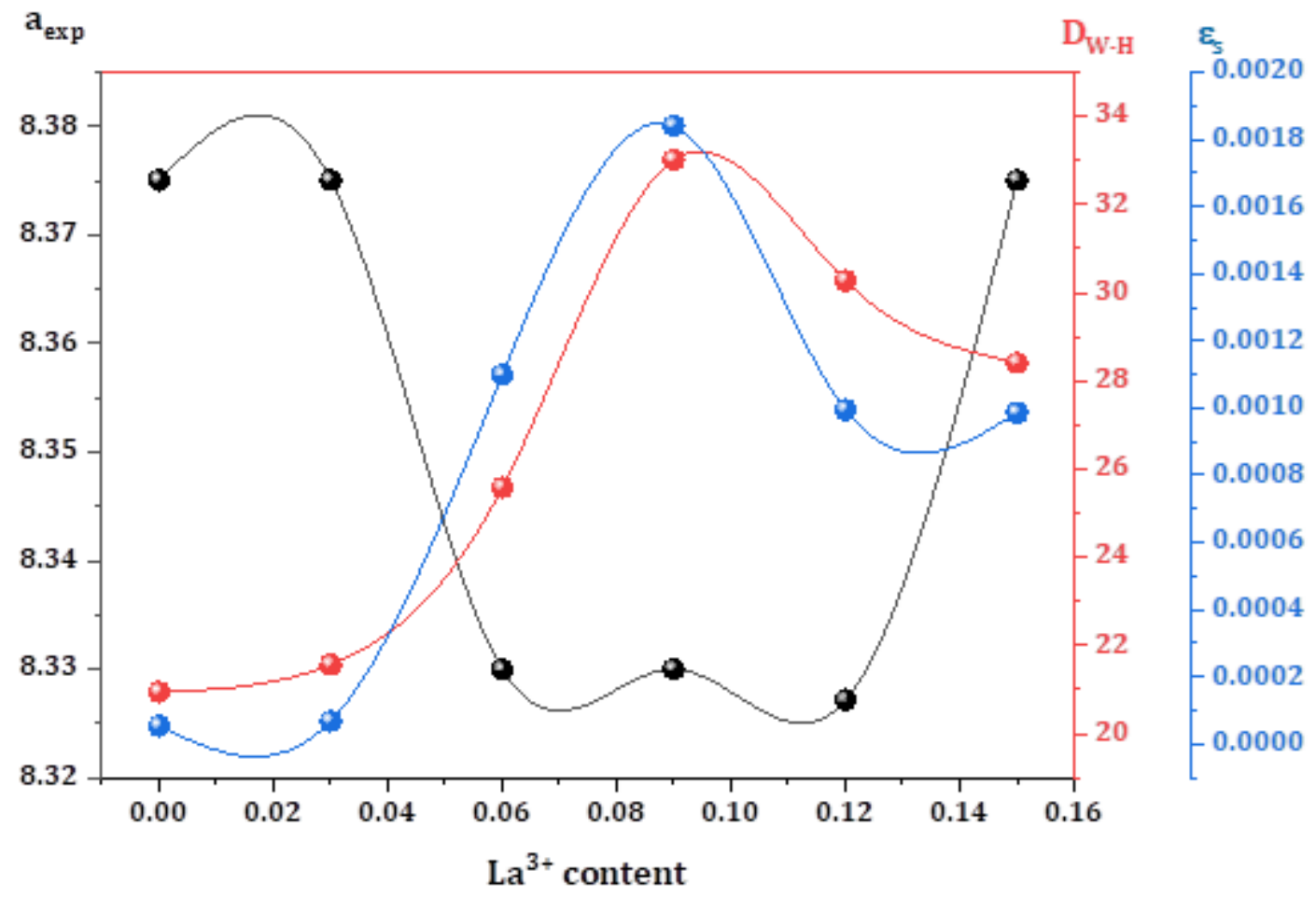

Loading [MathJax]/jax/output/CommonHTML/jax.js 
Figure 2

Dependence of lattice constant (aexp), crystallite size (WD-H) and lattice strain of on La3+ content for CCL nanoferrites.
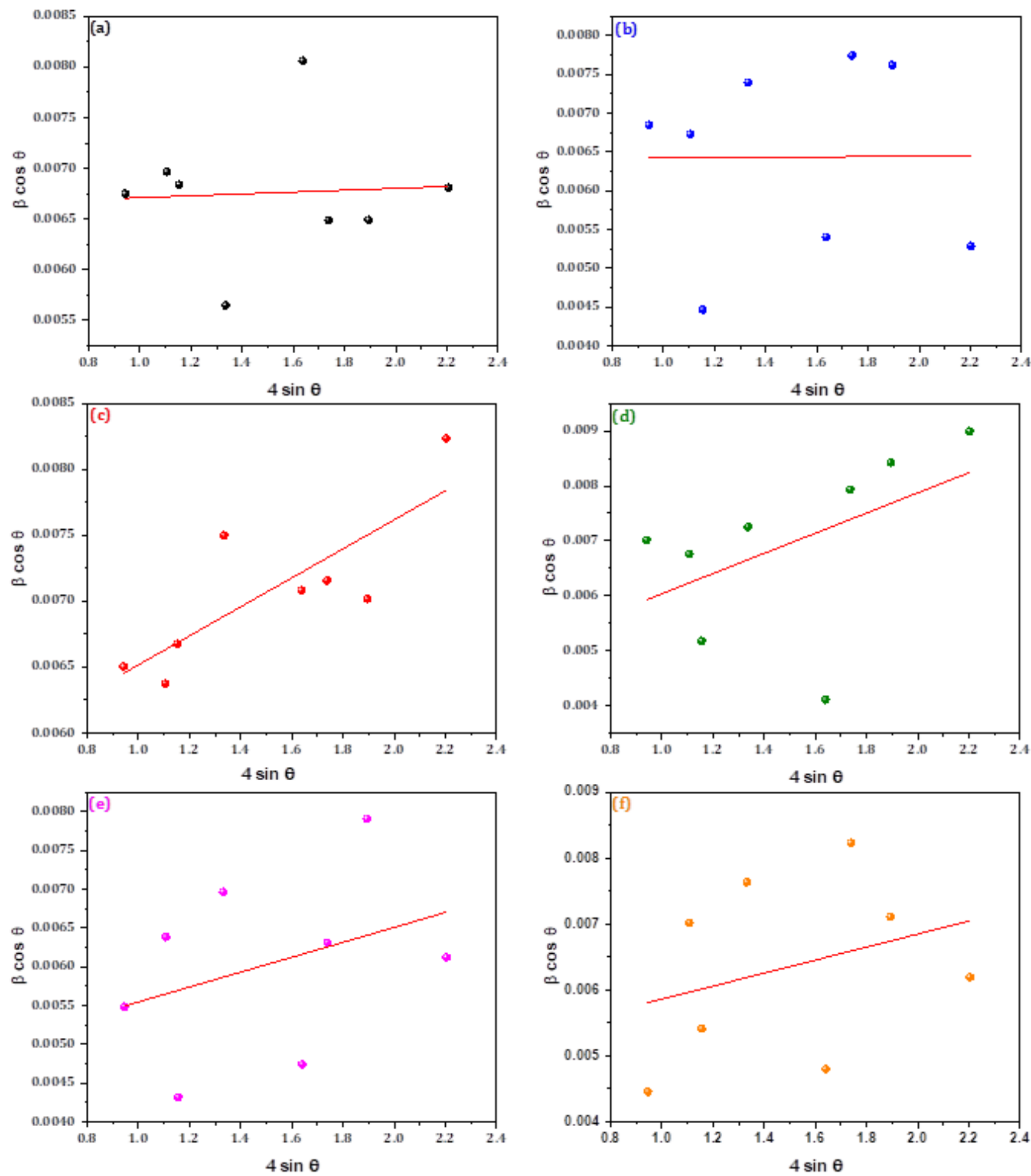

Figure 3

Loading [MathJax]/jax/output/CommonHTML/jax.js $(0.00 \leq x \leq 0.15)$ nanoferrites. 

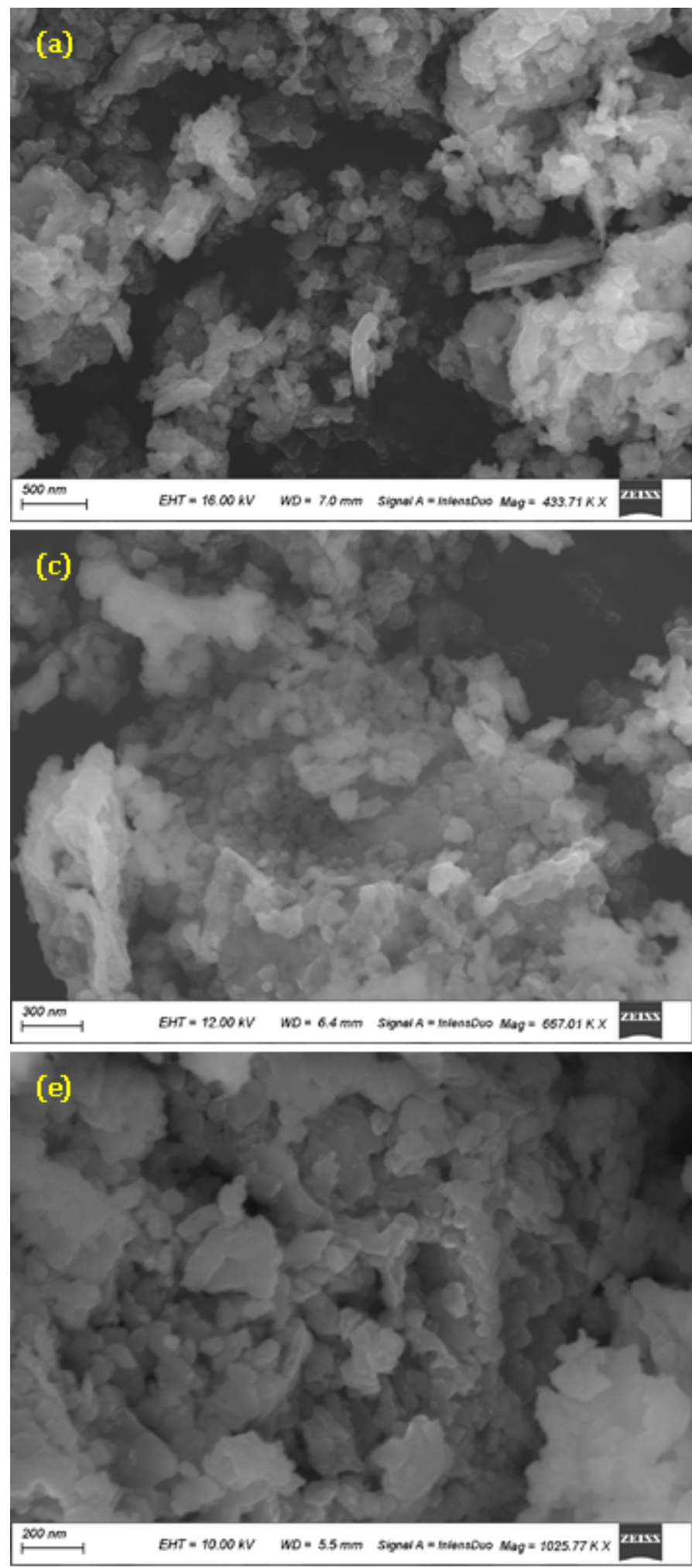

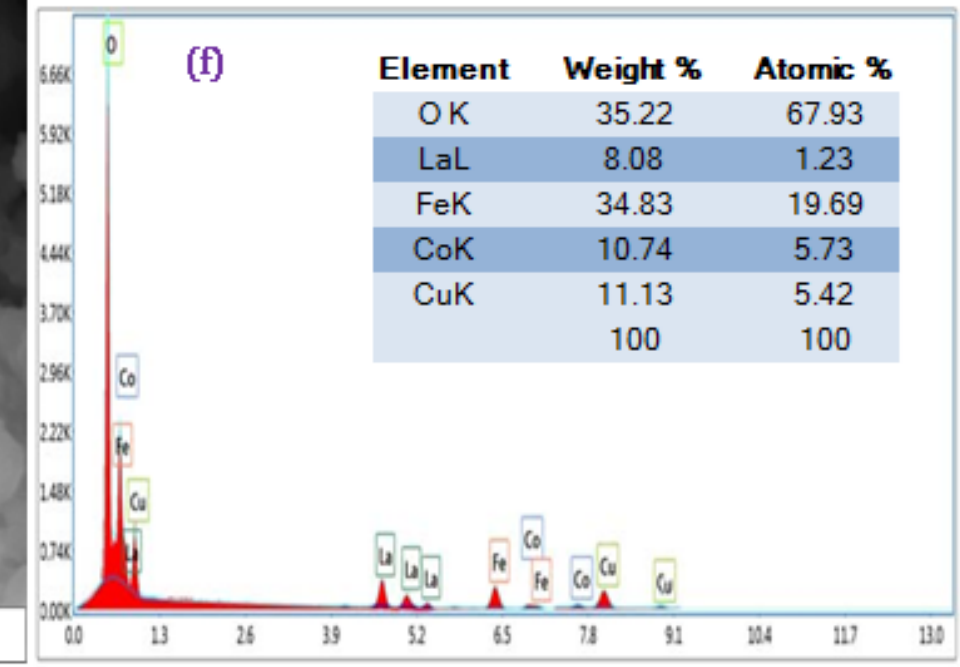

\section{Figure 4}

(a-f): FE-SEM-EDX micrographs of (a) Co0.5Cu0.5Fe2O, (b) Co0.5Cu0.5La0.09Fe1.9104 and (c) Co0.5Cu0.5La0.15Fe1.8504 ferrite nanoparticles. 


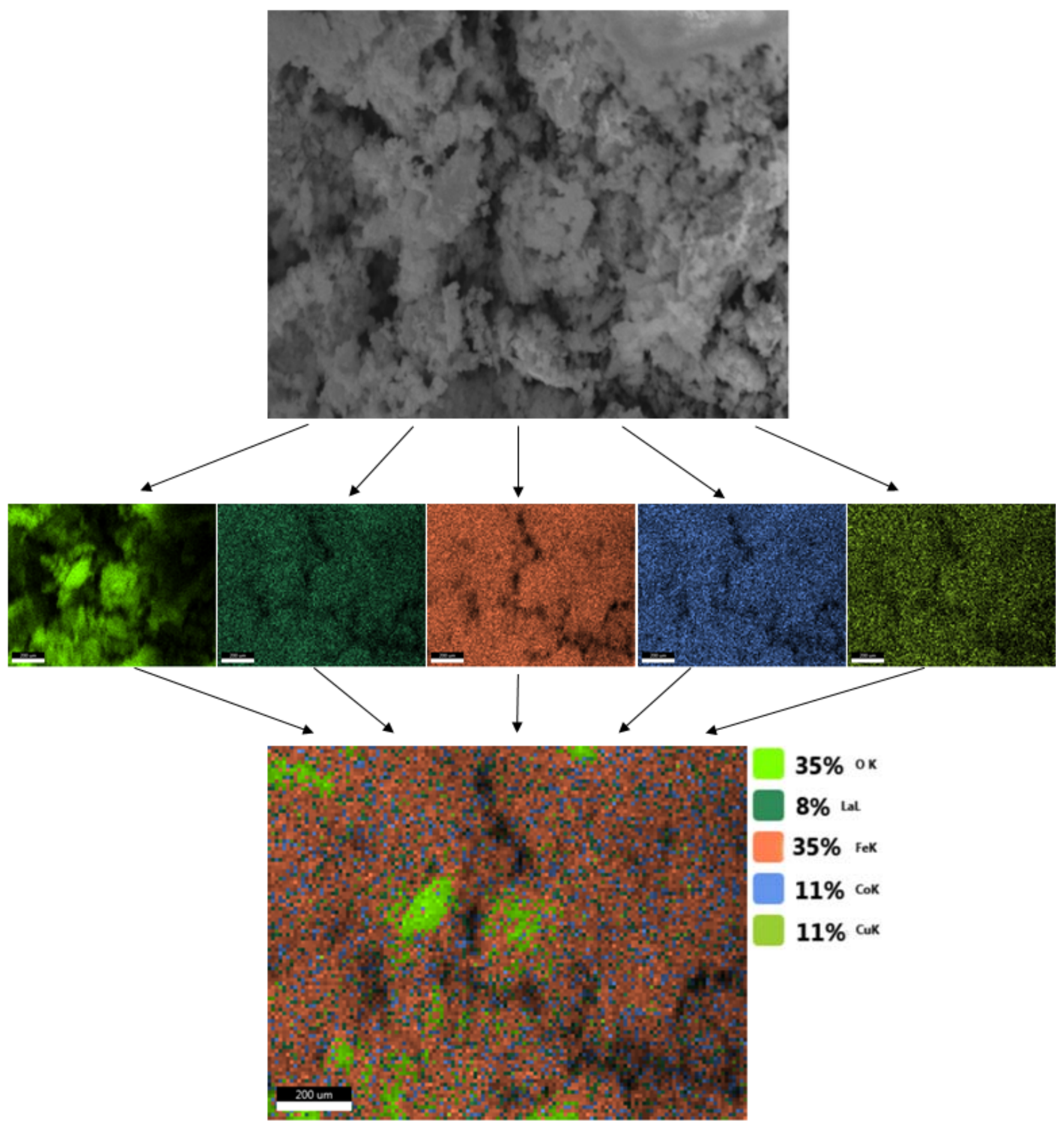

Figure 5

Typical STEM-EDX mapping for Co0.5Cu0.5La0.15Fe1.8504 ferrite nanoparticles. 


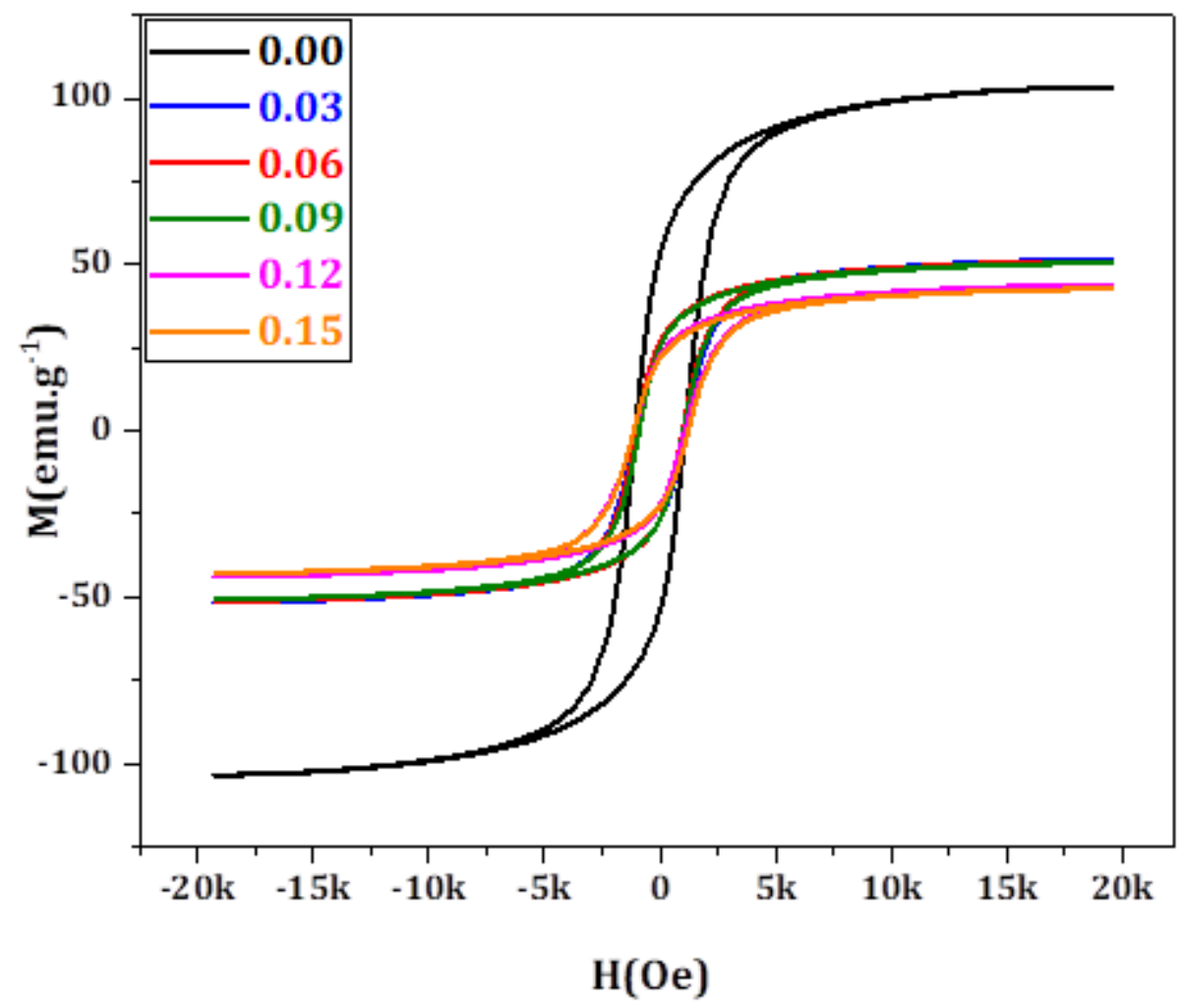

Figure 6

Hysteresis loops of CCL nanoferrites at RT.

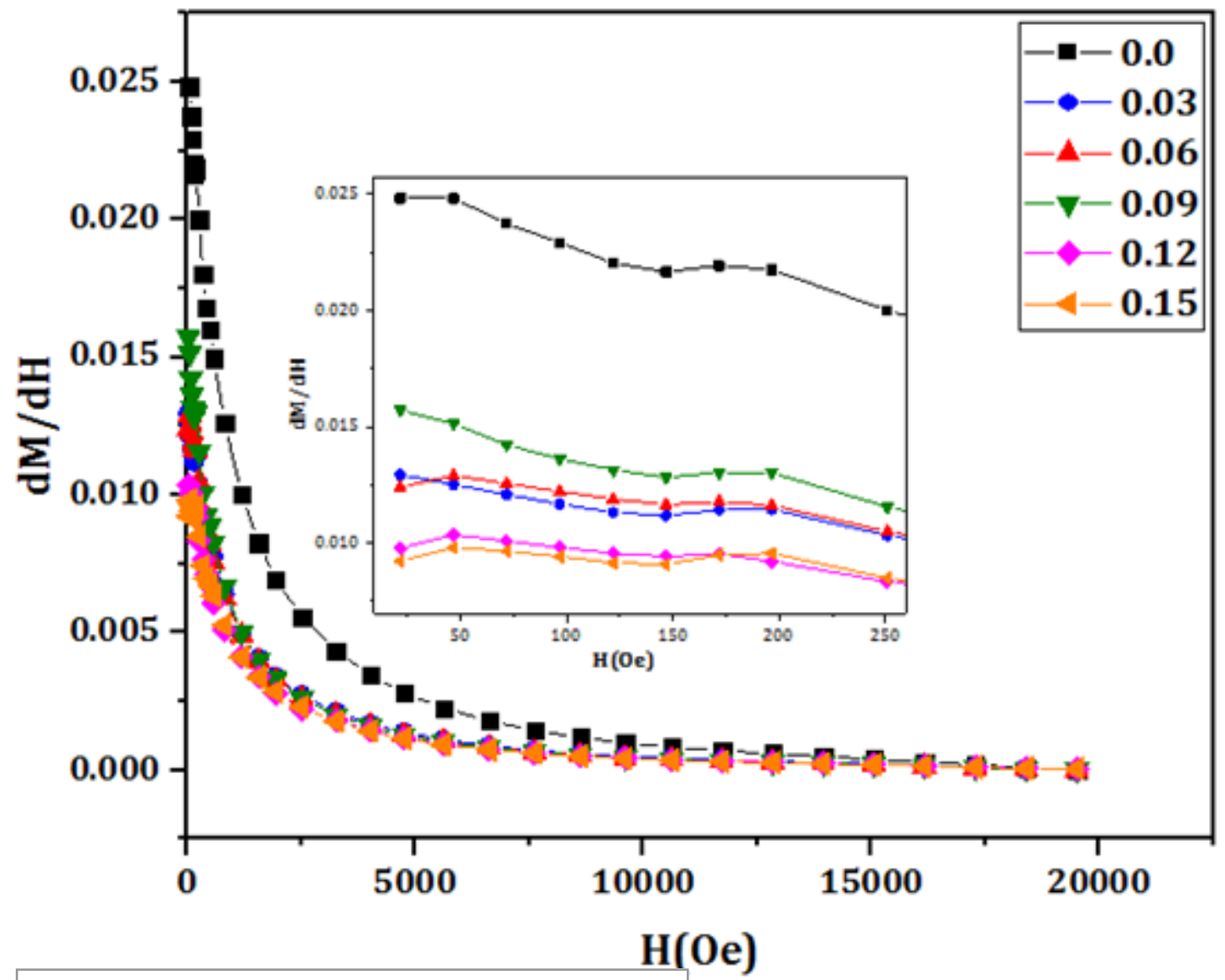

Loading [MathJax]/jax/output/CommonHTML/jax.js 
Figure 7

SFD response of CCL nanoferrites with its inset curve.
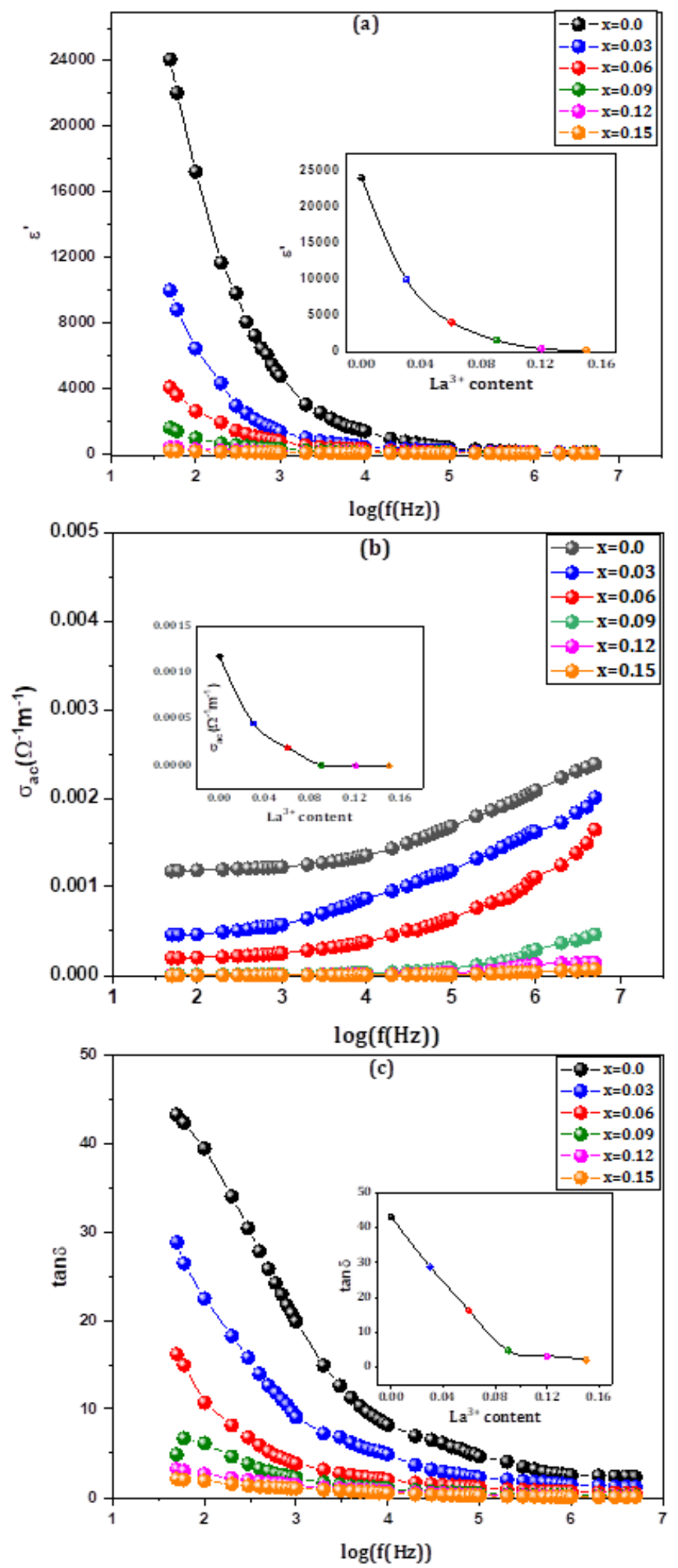

\section{Figure 8}

(a-c): The frequency dependence of (a) $\varepsilon^{\prime}$, (b) бac and (c) tan $\delta$ for CCL nanoferrites at RT. 


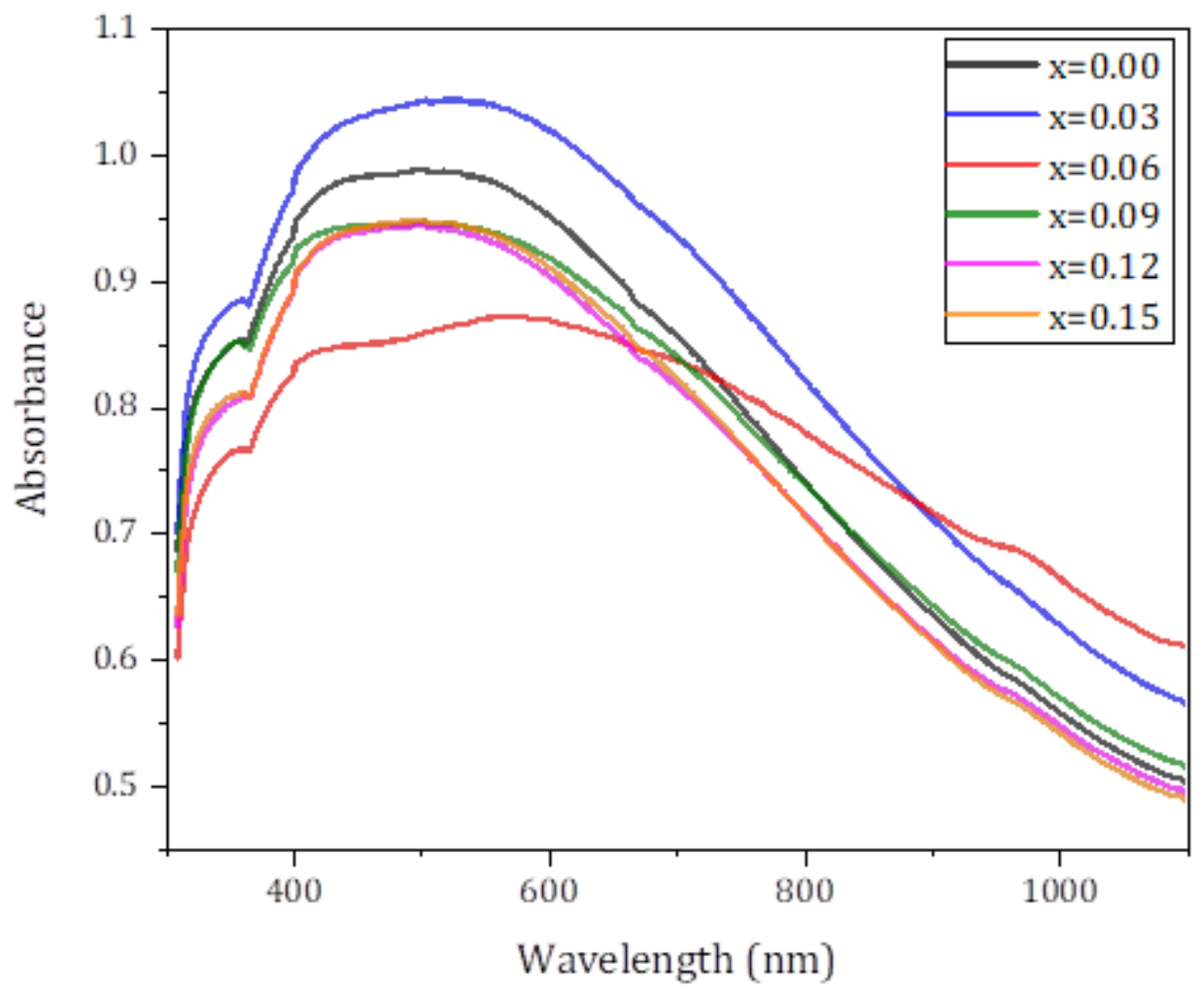

Figure 9

Optical absorption spectra as a function of wavelength for the prepared nanoferrite samples. 

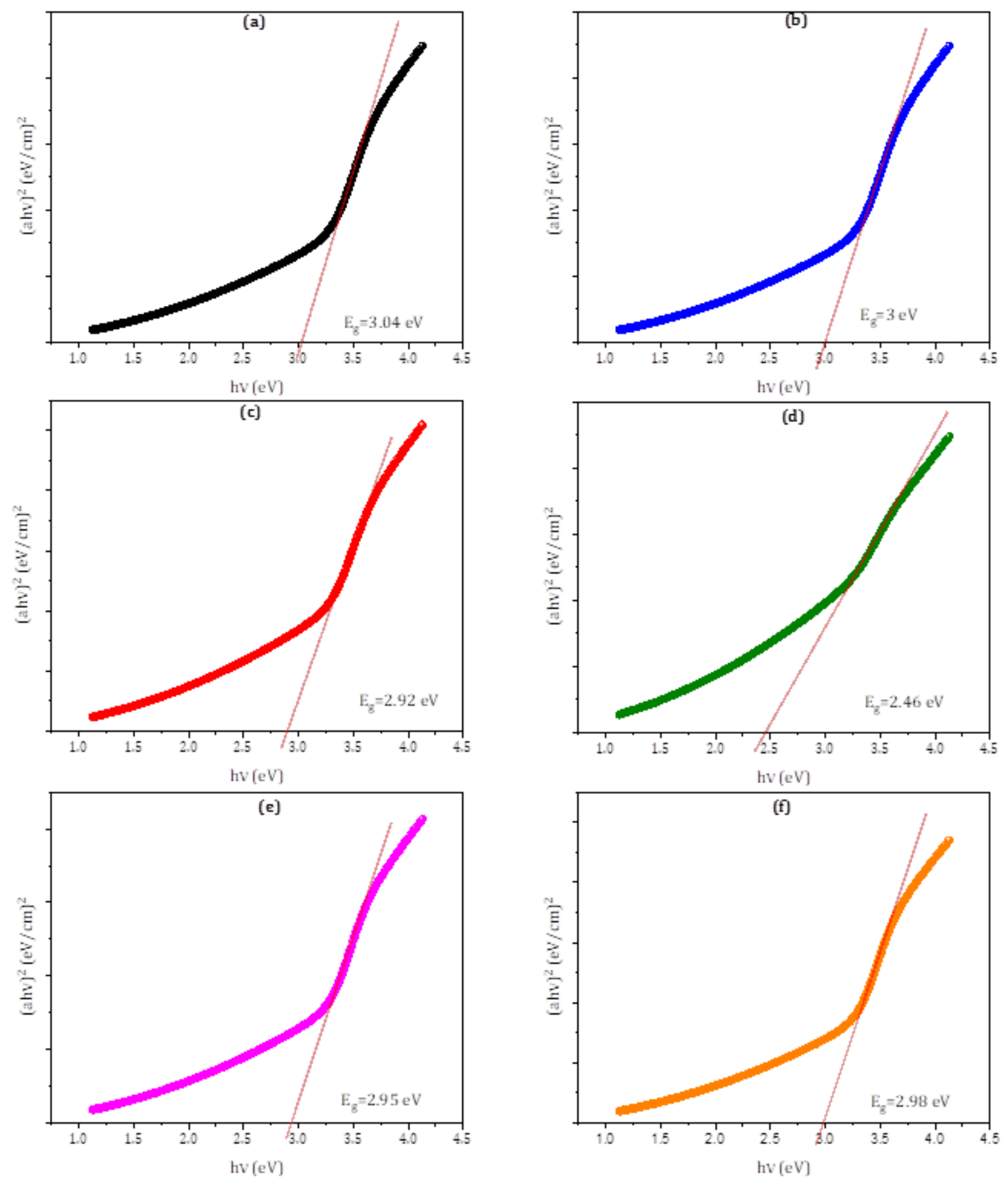

Figure 10

(a-f): Tauc's plot for all CCL nanoferrites. 


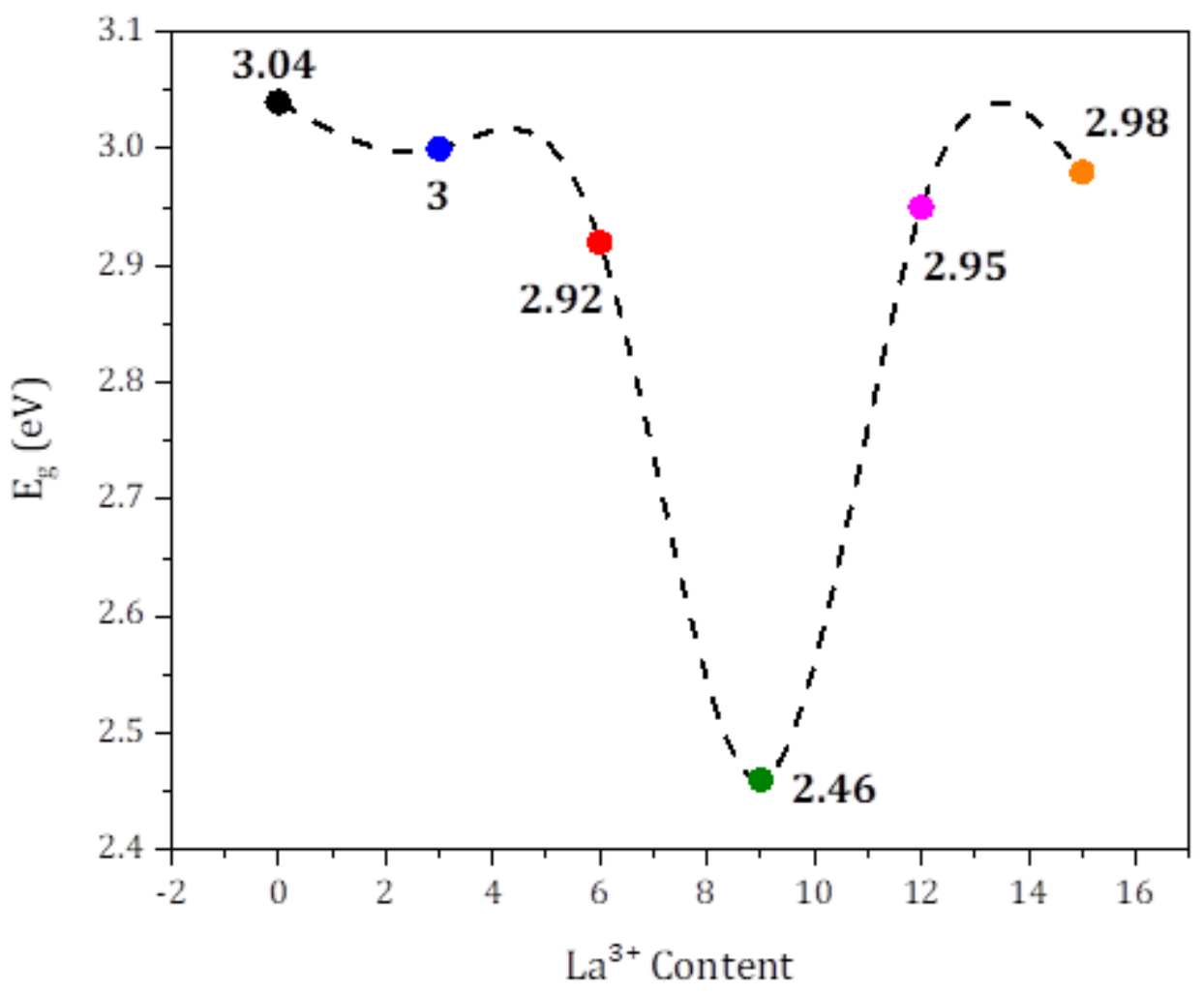

Figure 11

The change of Eg versus La3+ content. 

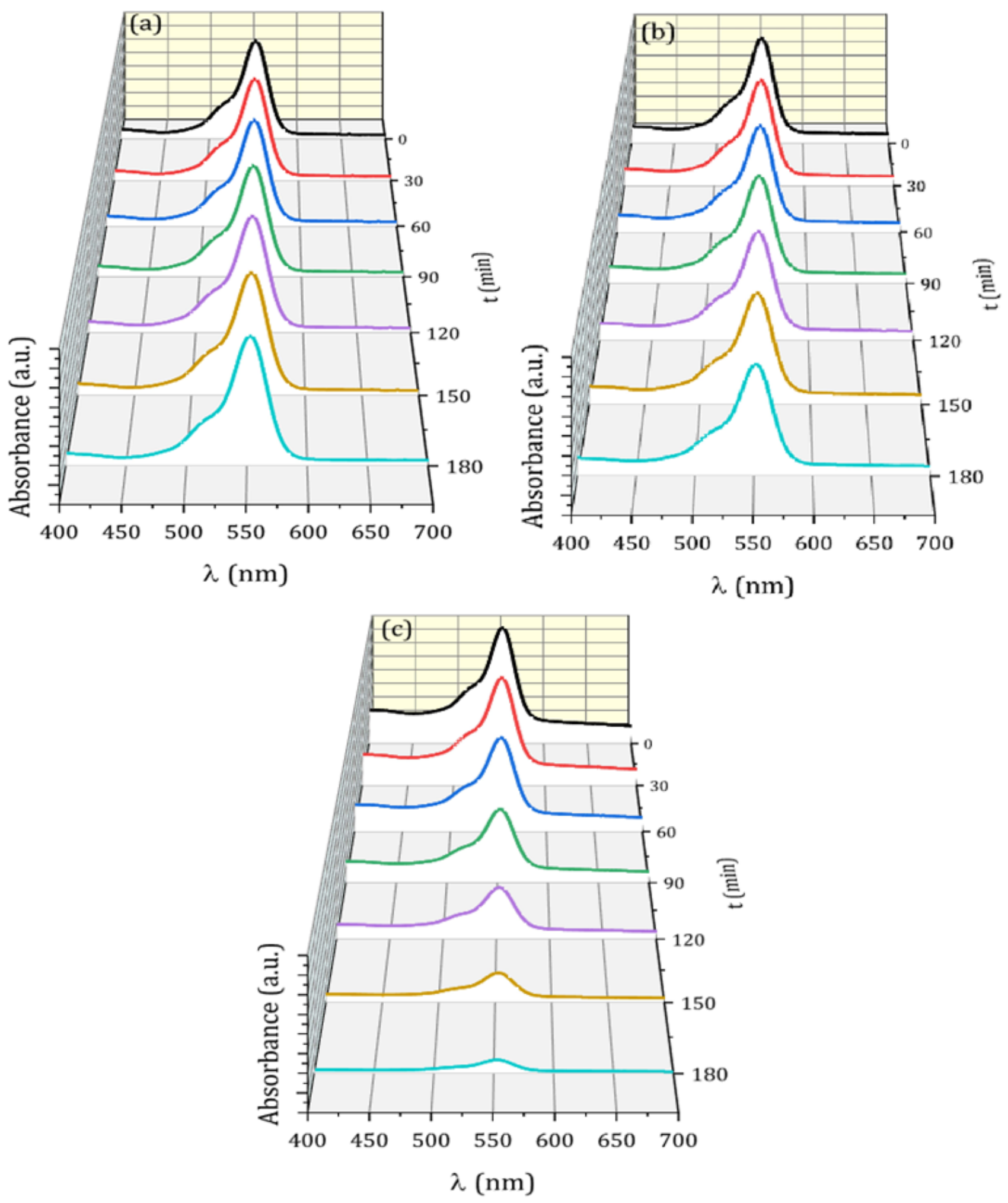

Figure 12

$(a-c)$ : Absorbance spectra of (a): pure RhB, (b): RhB with the Co0.5Cu0.5Fe2O4 nanoferrite and c): RhB with the Co0.5Cu0.5La0.09Fe1.9104 nanoferrite; taken at different photocatalytic degradation times (0180min). 


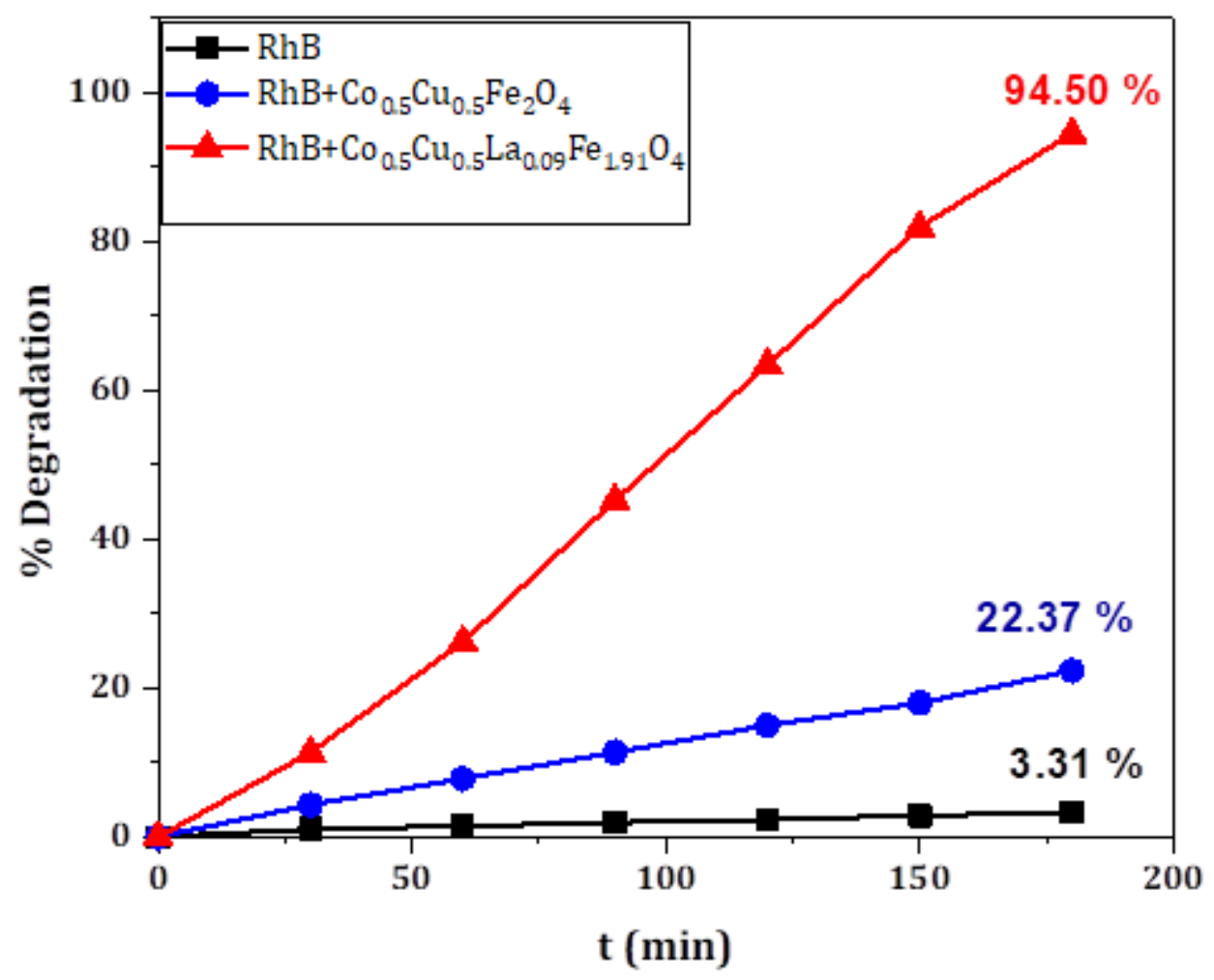

Figure 13

$\%$ degradation plot of pure $\mathrm{RhB}$ and $\mathrm{RhB}$ over $\mathrm{Co} 0.5 \mathrm{Cu} 0.5 \mathrm{SmxFe2-xO4;}$ ( 0.0 and 0.09$)$ nanoferrites, under simulated sunlight irradiation up to 180 min.
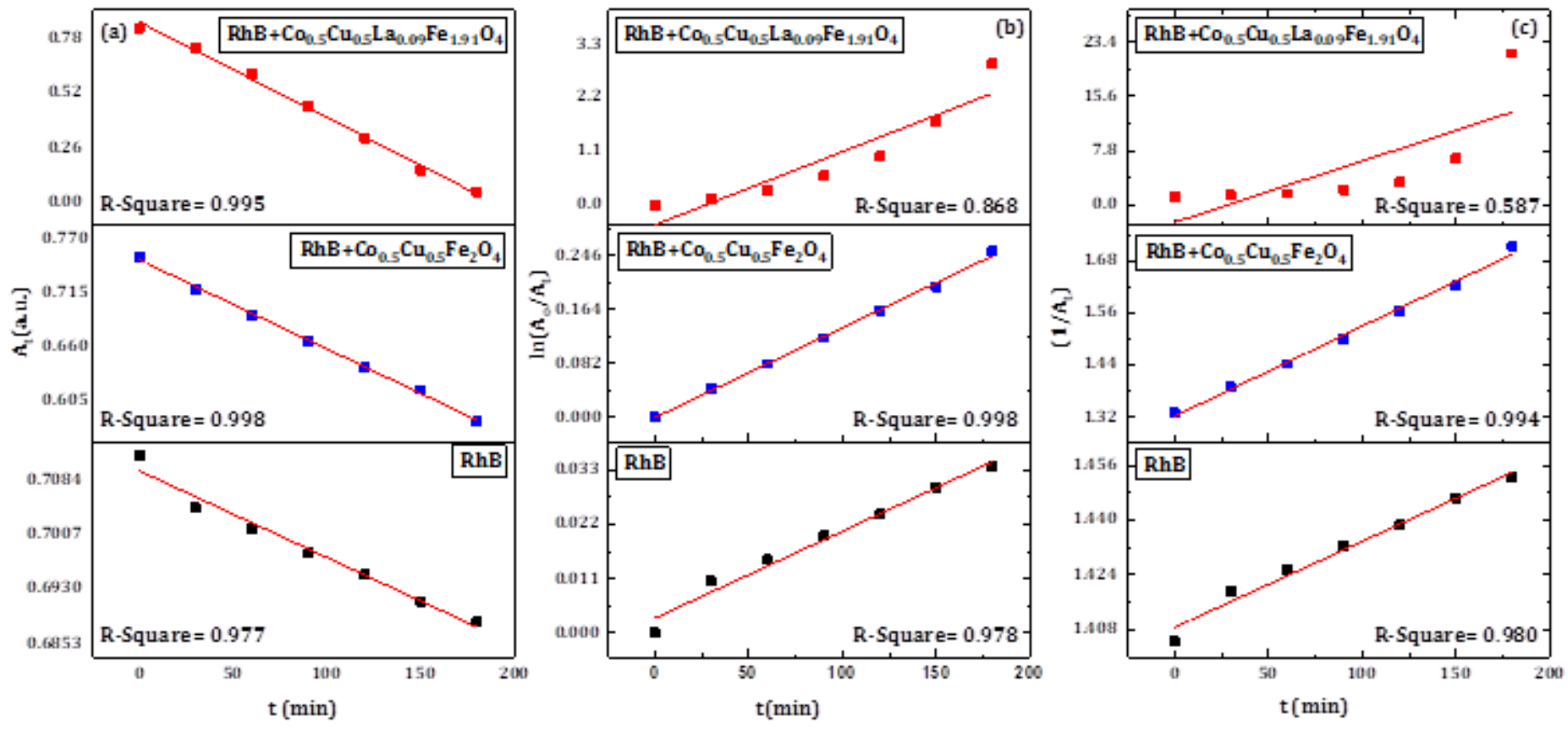

Figure 14 
(a-c): The plots of (a) At, (b) $\ln (A o / A t)$ and (c) (1/At) for RhB dye without and with Co0.5Cu0.5LaxFe2-xO4; $(x=0.0$ and 0.09$)$ as photocatalysts. 